\title{
PEDAGOGÍA DECOLONIAL: HACIA UNA COMPRENSIÓN/ACCIÓN EDUCATIVA EN LAS SOCIEDADES EMERGENTES ${ }^{1}$
}

\author{
Andrés Argüello Parra²
}

\author{
No creo que valga la pena vivir para ganar. \\ Creo que vale la pena vivir para hacer lo que la conciencia \\ te dicte que debes hacer, y no lo que te conviene \\ Eduardo Galeano, entrevistado por Barberà (2011)
}

\footnotetext{
1 El texto es un producto de investigación teórica en el campo de la filosofía de la educación. Se propone analizar las relaciones conceptuales entre la pedagogía y la decolonialidad, ante los retos culturales, éticos y epistemológicos de las sociedades emergentes. Para la construcción del artículo se tuvieron en cuenta dos tipos de fuentes: en primer lugar, el uso de materiales biblio-hemerográficos especializados, principalmente de Walter Mignolo, y otros exponentes de la perspectiva decolonial en las ciencias sociales. En segundo término, se utilizaron algunas entrevistas publicadas y otras realizadas por el autor del artículo durante su estancia posdoctoral como Visiting Scholar en el Center for Global Studies and the Humanities, en Duke University. Una versión de síntesis que retoma elementos de este trabajo ha sido previamente publicado en Argüello (2015).

2 Doctor en Pedagogía de la Universidad Nacional Autónoma de México, con estancia de investigación en el Institute of Sociology, University of Łódź, Polonia. Docente-investigador de la Universidad Santo Tomás (USTA, Colombia). Posdoctor en Educación, Ciencias Sociales e Interculturalidad de la Universidad Santo Tomás. Líneas de Investigación: Filosofía de la educación, pedagogías decoloniales, relaciones educación, política y ética. Email: mouneriano@yahoo.es
} 


\section{Presentación}

Múltiples situaciones sociales, políticas y culturales, acrecentadas por la vorágine histórica de los últimos años, han marcado el trasegar del tercer milenio como una época de transformaciones con innegables impactos en los modos de asumir el devenir de la existencia. Los desplazamientos paradigmáticos, que de ahí se derivan, socavan las estructuras de pensamiento y acción que se creían definitivas y estables para afrontar, sin anacronismos fácticos o simbólicos, un mundo exigente en constante cambio y lleno de incertidumbres.

En este escenario global, la educación, como campo de conocimiento y de acción social, pasa de sustentar un protagonismo autónomo, vertebral y anidado -como el que otrora tuvieron las iglesias y los gobiernos locales- a favorecer un coprotagonismo relacional, multifacético, como entidad y fuerza sociocultural, que exige revisar el papel de las instituciones, sus programas, sus relaciones con el orden establecido y, en especial, sus niveles de incidencia en la restauración de lo público, en el tejido de comunidades humanas efectivamente viables y en las inacabadas tareas de la personalización.

El proyecto modernidad/colonialidad-decolonialidad surge aquí como un itinerario de refundación epistémica a partir de los sentidos simbólicos, ancestrales y populares, presentes en toda comunidad humana, desde una mirada al reverso de las hegemonías y las oficialidades. Se trata, como ha planteado uno de sus exponentes, de un paradigma-otro de pensamiento desde la historia de la colonialidad (Mignolo, 2003).

Como se tratará más adelante, el pensamiento decolonial se estructura, especialmente, desde dos categorías insertas en la vigencia de los colonialismos: la colonialidad del poder y la diferencia colonial. La primera, desarrollada por el sociólogo Aníbal Quijano (2011), supone confrontar el régimen justificatorio de la universalidad, de la validez absoluta legitimadora de cualquier orden estamental. La segunda, hace mirar el lugar de la exclusión creada, del extrañamiento radical, que marca las fisuras sociales y humanas donde se produce el marco comprensivo de la misma colonialidad del poder y de los conocimientos fronterizos

El presupuesto que aquí se sostiene es que dentro de la perspectiva decolonial aplicada a la educación se puede descubrir un horizonte interpretativo para emprender sus propias tareas y desafíos ante la emergencia de (nuevas) identidades y sociedades. Por ello, en el presente trabajo se buscan definir los fundamentos teóricos que permiten 
establecer relaciones entre educación y decolonialidad, así como sus implicaciones en la ética, la política y el entramado cultural, para una concepción alternativa de civilización.

El trabajo se divide en tres grandes secciones: en la primera se presenta un panorama del planteamiento decolonial, sus antecedentes, condicionantes y características; en la segunda se expone de modo general el proyecto modernidad-decolonialidad en diálogo con algunos abordajes educativos, en especial, de tipo sociocultural y político; y, finalmente, a modo de propuesta de didáctica decolonial, en la tercera sección se desarrollan algunos postulados necesarios para la configuración de una pedagogía en sociedades emergentes.

\section{Panorama del planteamiento decolonial}

\section{Introducción: El reverso de la historia}

Para apreciar mejor el estatuto conceptual de la decolonialidad y sus referencias contemporáneas, se debe contemplar el registro transicional de las sociedades que es una de las características en el avance epistemológico del tercer milenio. En efecto, el acontecer del siglo XXI ha mostrado, con gran fuerza histórica y simbólica, la contingencia de los paradigmas sociales, la diversificación comprensiva de la vida y la sobre-exposición de la existencia humana asociada a las dinámicas de las transformaciones civilizatorias de la modernidad. Fenómenos como la capacidad de las redes sociales en Internet para provocar movilizaciones masivas en torno a las más diversas causas, lo cual conlleva la desterritorialización de la socialidad; la creciente celeridad en la producción y uso de las tecnologías de la información y la comunicación, que pone en cuestión los formatos convencionales de tiempo y de presencialidad (ubicuidad práctica); la dialéctica persistencia versus resistencia de los modelos económicos fundados en el mercado y el capital, que consolida las brechas de la iniquidad y forja la pauperización como un proyecto social normalizado; la radicalización de las urgencias éticas en la relación ser humano-sociedad-naturaleza, donde aparecen inusitados cuadros de barbarie junto a renovados fundamentalismos; la manifestación de una mayor conciencia de la finitud y la indeterminación, que asigna una valoración monumental al presente; son, entre otros, indicadores de una época complejizada en su condición, alterada en sus patrones comunes de comportamiento y reconfigurada en sus modos de socialización. 
Tal sistema de transformaciones históricas contemporáneas viene apuntalado por un marcado juego de contradicciones. Antiguas paradojas se cargan de nuevo significado: notorio progreso técnico pero frágil desarrollo de estructuras éticas consistentes, lo cual mantiene vivo el fantasma de guerras atroces sobre los pueblos; máximas ganancias financieras concentradas frente a débiles beneficios cívico-sociales generalizados: proyectos de riqueza extrema que contrastan con el salvajismo urbano, la marginación y el olvido rural; acumulación y circulación informacional avasallante pero esquivas vinculaciones entre conocimiento y desarrollo humano integral para todos: la «ilustrada ignorancia» donde los avances de la ciencia no parecen traducirse en mejores condiciones de vida, acceso pleno a los servicios públicos básicos ${ }^{3}$ y respeto efectivo a los derechos fundamentales; máximo control y aseguramiento de la calidad de los productos y servicios contra inevitables descalabros del azar... El tercer milenio se muestra, pues, como el mundo de los antagonismos, es decir, el gran escenario donde cohabita el todo y la nada, el ser y el no-ser, la vida y la muerte.

Ciertamente, no por ser el tercer milenio sino porque nunca la condición humana pareció estar tan expuesta, el mundo no solo ha cambiado en sus paradigmas de explicación, control y predicción, relacionados con el modelo lineal de la historia, sino que ha modificado con ello la comprensión y praxis de los actores sociales, las formas de organización cultural, los mecanismos de participación política, las estructuras axiológicas (éticas, creencias, estéticas, etc.) con sus representaciones y, en consecuencia, el papel de las instituciones en la esfera pública de cara a un proyecto compartido de humanidad. De este modo, el continuo cambio de la historia del presente, que llamamos registro transicional, junto a la condición humana expuesta, exige la conversión de las estructuras de conocimiento y de praxis heredadas de la modernidad, que quizás pudieron ser suficientes bajo los estrictos cánones que ella impuso, pero que hoy no responden a las espacialidades y a las temporalidades emergentes como definidoras de los nuevos sistemas relacionales.

3 Por ilustrar, un ejemplo, en el discurso de apertura de la Cumbre del Agua 2013, realizada entre el 8 y el 11 de octubre de 2013 en Budapest, el secretario general de la ONU, Ban Ki-moon, declaró que casi mil millones de personas en el mundo no cuentan con un sistema sanitario adecuado (Recuperado de: http://www.budapestwatersummit.hu/. Octubre 14 de 2013). 


\section{Ciencias sociales, epistemología y giro decolonial}

En el panorama del reverso de la historia, se instala el giro epistémico de las ciencias sociales, esto es, la necesidad de repensar sus fundamentaciones, con base en alternativas gnoseológicas vinculantes de la experiencia humana, pues la construcción del conocimiento está directamente relacionada con las condiciones que afectan la existencia y con los imperativos éticos que reclaman las sociedades emergentes.

La confrontación epistémica fundante se genera por una visión unidimensional de las realidades que disuade su condición de complejidad, con sus planos y niveles, donde fluyen trayectorias de vidas personales y colectivas, sistemas de creencias, cuerpos valorativos, conglomerados ético-morales, en fin, universos paralelos simultáneos de la existencia humana y de las culturas, donde se instala la pluralidad de conocimientos y prácticas con la consecuente imposibilidad del pensamiento único de la modernidad.

La refundación epistemológica como «reflexividad de la ciencia social» requiere un pensamiento integrador que establezca nuevas apreciaciones en torno al conocimiento y el llamado «objeto de estudio», la relación simbiótica sujeto-objeto, la potencia del vínculo sujeto-sujeto, y, en general, la revisión de las relaciones lógicas diseccionadoras y fragmentarias de la realidad.

El tránsito hacia un formato comprensivo-inductivo, más que hipotético-deductivo, significa desarrollar, en palabras de Haraway (1995):

Una epistemología de la localización, del posicionamiento y de la situación, en la que la parcialidad y no la universalidad es la condición para que sean oídas las pretensiones para lograr un conocimiento racional. Se trata de pretensiones sobre las vidas de la gente, de la visión desde un cuerpo, siempre un cuerpo complejo, contradictorio, estructurante y estructurado (p. 335).

Para asumir este empeño, distanciado de la tradición crítica moderna occidental, De Sousa (2011) propone la categoría de epistemologías del Sur, esto es, el desplazamiento hacia epistemes-otras allende la fijación del logos anglo/eurocéntrico ${ }^{4}$. No es el sur geográfico

4 La categoría Epistemología del Sur hace referencia a «el reclamo de nuevos procesos de producción y de valoración de conocimientos válidos, científicos y no científicos, y de nuevas relaciones entre diferentes tipos de conocimiento, a partir de las prácticas de las clases y grupos 
sino el territorio simbólico y vital alentado por la fuerza de múltiples movimientos sociales, indígenas, de género, afrodescendientes, naturalistas, entre otros, que apuntan a proyectos de autogestión, organizaciones económicas populares y luchas por la dignidad propia de los pueblos, el cosmos e identidades. Como ha señalado Mignolo (2003), «estos proyectos forman un paradigma otro porque tienen en común la perspectiva y la crítica a la modernidad desde la colonialidad» (p. 27).

A diferencia de la dinámica anglo/eurocéntrica, De Sousa apunta que:

los movimientos del continente latinoamericano, más allá de los contextos, construyen sus luchas con base en conocimientos ancestrales, populares, espirituales, que siempre fueron ajenos al cientismo propio de la teoría crítica eurocéntrica. Por otro lado, sus concepciones ontológicas sobre el ser y la vida son muy distintas del presentismo y del individualismo occidental (2011, p. 27).

Las epistemologías del Sur se sustentan, principalmente, en dos premisas complementarias: el ensanchamiento de cosmovisiones pues «la comprensión del mundo es mucho más amplia que la comprensión occidental del mundo», lo cual confronta las posiciones unilaterales y hegemónicas que pretenden anular toda posibilidad del mundootro. En segundo término, la inmensidad de alternativas de vida, de convivencia con otros en la diferencia y de interacción con el planeta, pues, como afirma De Sousa:

la diversidad del mundo es infinita, una diversidad que incluye modos muy distintos de ser, pensar y sentir, de concebir el tiempo, la relación entre seres humanos y entre humanos y no humanos, de mirar el pasado y el futuro, de organizar colectivamente la vida, producción de bienes y servicios y el ocio (De Sousa, 2011, p. 35).

Es así como los intelectuales y activistas de la apuesta decolonial han estudiado las conexiones tácitas o manifiestas entre el proyecto epistemológico de la modernidad, el anglo/eurocentrismo y la colonialidad sobre los distintos estamentos de los fenómenos sociales. En sus análisis, escrutan las conjunciones determinantes entre los cimientos de

sociales que han sufrido de manera sistemática las injustas desigualdades y las discriminaciones causadas por el capitalismo y el colonialismo» (De Sousa, 2011, p. 35). 
la colonialidad y las formaciones de la modernidad. Sin ser el interés del presente trabajo exponer las minucias de esta articulación, bastará recordar aquí algunos postulados centrales para efectos de contextualización conceptual.

En primer lugar, epifenómeno de las geopolíticas del conocimiento, se encuentra la positivización de las disciplinas concebidas como ciencias sociales, consecuencia de la configuración histórico-cultural del liberalismo económico y político, en tanto modo hegemónico de organización de la vida individual y colectiva desde la invención de Occidente. De esta forma, las ciencias sociales, como señala Lander (2011):

tienen como sustrato las nuevas condiciones que se crean cuando el modelo liberal de organización de la propiedad, del trabajo y del tiempo dejan de aparecer como una modalidad civilizatoria en pugna con otra(s) que conservan su vigor, y adquiere hegemonía como la única forma de vida posible (p. 26).

En efecto, un dominio típico de la colonialidad es la epistemología moderna, con su antropocentrismo y su racionalismo radical. La unilateralidad explicativa de las ciencias sociales aparece asociada a cierta cosmovisión dominante que destaca la segmentación de las partes frente a un todo válido, radicaliza la división sujeto-objeto e impulsa la reificación de los procesos humanos tanto en sus entidades individuales como colectivas.

A partir de este imperio de la razón occidental, apropiado por las llamadas ciencias exactas y experimentales, las ciencias sociales asisten a una primera hora marcada por la dominación de estas lógicas. La edad de oro de la Razón moderna, cuando el programa evolutivo de la Historia quiso ser Uno, marcó la pauta de un gran proyecto civilizatorio y, en él, del método científico clásico que procuró las formas de control sobre todos los ámbitos de la naturaleza. Es la ciencia basada en la fundamentación matemática, en la estricta separación sujeto-objeto, en la demostración racional hipotético-deductiva y en el uso racionalizado de la experimentación.

Las ciencias sociales, entonces, serían consideradas «ciencia» si lograban acatar el manual programático canónico sobre la base de una epistemología del hecho social puro, independiente del sujeto. Tal era la condición para que los fenómenos sociales pudiesen ser explicados desde los criterios validados por el método científico, al margen de todo contenido valórico o expresión cualitativa.

No obstante, a pesar de que dicho modelo permitió un desarrollo importante de la actividad científica general, sus efectos no solo impactaron el plano epistémico sino la 
organización política, social y cultural. Una consecuencia insoslayable de esa unificación de las racionalidades fue la violencia misma de la dominación en sus múltiples facetas, a través de los formatos del exterminio o la adaptación forzada.

Pero, como es de esperarse, si un paradigma se impone a costa de otros, la anulación o integración de los ámbitos «desvinculados» de la matriz canónica no ocurre instantáneamente puesto que la «naturalización de la sociedad liberal de mercado» (Ibídem, p. 26) no implica la eliminación práctica de las múltiples formas concretas de existir, de conocer, de representar y reconstruir.

De este modo, el meollo del giro epistémico de las ciencias sociales es procurar que no toda la producción científica se pueda ponderar y legitimar según las concepciones positivistas de «utilidad» o «validez», o los patrones hegemónicos de «verdad», «rendimiento»y «eficiencia» del paradigma tecno-económico liberal. Como lo ha defendido De Sousa (2003), existen conocimientos-otros «derivados de otras prácticas, otras racionalidades y universos culturales» (p. 237), que no pueden obviarse y que expresan la hora vigente del quehacer epistemológico de las ciencias sociales. En el horizonte decolonial, como se retomará más adelante, se ubican aquí las categorías de pensamiento fronterizo y conocimientos subalternos.

De esta manera, las ciencias sociales han tenido que enfrentar la polifacética tarea de deconstrucción (y no sólo al estilo moderno europeizante) de los postulados hegemónicos del conocimiento «objetivo, científico y universal» al tratar el hecho social y los fenómenos humanos como entidades complejas interconectadas más que como estrictos «objetos de estudio». Así se aprecia, por ejemplo, como señala Lander (2011), además de las destacadas contribuciones de carácter no eurocéntrico en América Latina y el Caribe, en las

múltiples vertientes de la crítica feminista, el cuestionamiento de la historia europea como Historia Universal, el desentrañamiento de la naturaleza del orientalismo, la exigencia de «abrir las ciencias sociales»; los aportes de los estudios subalternos de la India, la producción de intelectuales africanos [...], y el amplio espectro de la llamada perspectiva postcolonial que encuentra especial vigor en muchos departamentos de estudios culturales de universidades norteamericanas y europeas (pp. 16-17).

Dicho en términos generales, en la crítica a la modernidad se pueden identificar, por lo menos, cuatro trayectorias. Una crítica de tipo eurocéntrica (deconstrucción de pensamiento) relacionada con las contribuciones de la Escuela de Frankfurt, el 
postmodernismo y el posestructuralismo; un grupo de corrientes que emergen desde las colonias europeas y los nuevos territorios emancipados (poscolonialismo); la crítica que brota de territorios culturales no directamente colonizados, como Asia del Este y los países islámicos (dinámica de des-occidentalización); y, los estudios originados en destacadas «regiones modernas», como Estados Unidos o Europa Occidental, en los cuales emergen los estudios étnicos americanos, la tendencia «Europa negra», la refundación de los arquetipos de la sexualidad y el establecimiento de la perspectiva queer, entre otras.

En el dinamismo de esta maduración epistémica de las ciencias sociales, para confrontar la colonización del conocimiento, un aporte constitutivo se debe al pensamiento decolonial que surge como una variante del poscolonialismo, la desoccidentalización y los «estudios subalternos» emergentes. O, podría decirse, como un campo epistémico de otredad alimentado, además, por las distintas tradiciones del pensamiento en América Latina: «Un "paradigma otro” es en última instancia el nombre que conecta formas críticas de pensamiento “emergentes» (Mignolo, 2003, p. 20) dentro de las expansiones imperiales/ coloniales de las distintas épocas.

Para hablar de la perspectiva decolonial se parte, por presupuesto lógico, de un estado de colonialidad, que no es solo el colonialismo de época marcado, por ejemplo, por la primera fase del dominio de los imperios europeos del siglo XVI sobre el Nuevo Mundo. La colonialidad, que prepara la resignificación de las ciencias, es, principalmente, un programa de historización totalizante, un modo canónico de hacer vida, de crear pensamiento, de validar creencias y prácticas, desde esquemas de dominación enraizados en la cultura, el poder y el conocimiento (epistemología), en orden a radicalizar la cosmovisión «oficial» sobre la base de los formatos explicativos modernos. Así, la colonialidad es una fuerza dominante que paraliza la diferencia antropo-cultural y que se inocula en todas las experiencias de la vida cotidiana.

Para ilustrarlo mejor, en el siguiente apartado se recogen estos conceptos centrales de la perspectiva decolonial y se establecen relaciones con el ámbito de la educación.

\section{Acercamiento al horizonte colonial/decolonial: génesis y características}

¿Qué se encuentra en la estructura de fundación de la colonialidad? Ante esta pregunta, Mignolo plantea el carácter colonial de la historia moderna en Occidente (Mignolo, 2011). De esta forma, conecta el proyecto histórico de la Modernidad con los legados coloniales y sus 
notas triunfalistas de salvación, progreso, bienestar y seguridad, que, tradicionalmente, le han estado asociadas.

La Modernidad, desde este punto de vista -como programa histórico y eje articulador de las formas de organización social e individual imperantes en Occidente-, al apoyarse en la magnificencia de la Razón y en los modos de producción para el rendimiento acumulativo, transmite una impronta de univocidad totalizante, una reconfiguración del Absoluto (meta-narrativa histórica de Hegel), que se traduce como el proyecto oficial de la economía (centrado en las premisas del capital financiero y el consumo), la política (estados-nación que aseguran el orden y la democracia), la epistemología (conocimiento según el «rigor científico» válido), la pedagogía (educación institucional principalmente para el trabajo en tanto instrumento de la economía capitalista), entre otras dimensiones.

El primer concepto que aquí anida es el de colonialidad global o matriz colonial del poder que muestra, desde las geopolíticas del conocimiento, cómo una historia local determinada llega a establecerse como la única, es decir, una historia local que, teniendo a su favor las maquinarias del poder dominante, se transforma en una historia universal: una filosofía de la historia fundada en la razón moderna, con su consecuente colonización del tiempo y el espacio (Mignolo, 2012). Así, la modernidad en su autodefinición como modernidad (Mignolo citado en Walsh, 2003, pp. 1-2) produce la dificultad de comprender, apreciar, valorar y legitimar lo que está fuera de las coordenadas canónicas de ese horizonte de pensamiento y de vida5.

Se trata, ciertamente, de un proceso complejo y de larga duración, no solo en sus elementos constitutivos sino en las modalidades de prevalecer en medio de las transformaciones del espíritu humano: «Según han sido las imágenes del mundo vigentes en cada época, así los pretextos del colonialismo se han teñido con fuertes matices trascendentales a través de generalizaciones y conclusiones ad hoc» (Mignolo, 2003, p. 8). Mignolo resume los grandes hitos del proyecto de la modernidad/colonialidad en las Américas a partir de tres segmentos, que se enuncian aquí para ilustración general del concepto de colonialidad global ${ }^{6}$.

5 Para el proyecto decolonial no es posible concebir conocimientos deslocalizados que, en su pretensión de absoluta universalidad, se pretendan válidos para todos los casos y circunstancias: «La "historia" del conocimiento está marcada geohistóricamente y además tiene un valor y un lugar de “origen”». (Mignolo citado en Walsh, 2003, p. 3).

6 No es la intención de este apartado desarrollar extensivamente los procesos geohistóricos que aquí se refieren, lo cual ya ha sido realizado de manera magistral por autores como Quijano, 
El momento fundacional es la etapa imperial del siglo XVI, o de la misión cristianizadora, en la cual se destaca «la expulsión de los judíos, la derrota de los moros y la expansión por el Atlántico» (Mignolo, 2011, p.74). Desde esta pretensión expansionista, alentada por el referente cristiano-europeo de «llevar la conversión a los pueblos», «todos pasaron a configurarse, en el imaginario occidental cristiano, como la diferencia (exterioridad) en el interior del imaginario» (Ibídem, p. 74). Se establece, entonces, la lógica colonial de la alterización, que define a «el otro» como el no-ser o, en el mejor de los casos, como el ser-incompleto, con respecto al otro-absoluto.

La misión cristiana contenía, además, una pretensión civilizadora, es decir, sus alcances no solo conllevaban el sustrato ideológico de la religión pues transmitía un modelo económico que contribuyó a «construir el imaginario del circuito comercial del Atlántico» (Ibídem, p. 74), el cual sería determinante para la posterior consolidación del capitalismo7. Esta configuración colonial del vínculo trabajo-capital tuvo impactos inevitables en el ordenamiento social estratificado y en la definición de nuevas exterioridades. En efecto, «fue con y a partir del circuito comercial del Atlántico cuando la esclavitud se convirtió en sinónimo de negritud» (Op. cit., p. 81).

Un segundo hito en el desarrollo del proyecto modernidad/colonialidad en las Américas está marcado por el surgimiento del liberalismo y el periodo iluminista del siglo XVIII que, asumido como «el siglo de la razón», desplazó el imperio del cristianismo para convertirse en sí mismo en una «religión secular». Pensadores como Kant y Hegel alcanzaron una importancia singular en el progresivo tejido de concepciones en torno a la América (en este caso, solo Norteamérica) sumida en una minoría de edad, pero con visión de futuro en la dialéctica de la Historia absoluta que consideraba a Europa como el modelo del presente ${ }^{8}$.

Mignolo, Dussel y otros. En este punto, la ilustración de acontecimientos solo pretende ofrecer un marco situacional amplio de los conceptos que se proponen para la fundamentación del artículo.

7 Para explicar la matriz colonial del poder se debe apreciar el carácter omniabarcante del mismo. La misión civilizadora religiosa no solo comporta un esfuerzo de adoctrinamiento de las creencias sino una forma de organizar el poder político y la vida socioeconómica.

8 Para una ilustración concreta del fenómeno de la identificación del pensar con lo europeo, la idea del Nuevo Mundo como prehistoria y las formas coloniales de la universalidad engendrada en la filosofía moderna e ilustrada, se podrá ver el capítulo «América Latina y la particularidad de la universalidad europea» (Reyes, 2008, pp. 61-78). 
La misión civilizadora liberal-iluminista implicó también un proyecto político sobre la base del modelo de los estados-nación, la consolidación de los fundamentos «técnicos» de la democracia, el constitucionalismo y la conformación moderna de las repúblicas. Consecuencia de la expansión de los postulados políticos modernos, se fueron alentando los procesos de independencia de las colonias americanas que, justamente por adoptar el macroproyecto geo-político occidental, ajeno y deslocalizado, diluyó los presupuestos fundantes de autoctonía e hibridación que caracterizaban el mapa demográfico-cultural de las Américas. Si una primera estratificación social ya se había preparado por cuenta de la conquista del circuito comercial del Atlántico, esta se verá ahora consolidada por la colonialidad política efectuada sobre las condiciones raciales, tan características del «Nuevo Mundo».

Aquí se tejen los presupuestos del colonialismo interno y la pérdida de lo que Mignolo llama la doble conciencia criolla pues, «si los criollos blancos no se hicieron cargo de su doble conciencia [amerindia y afro-americana] se debió, quizás, a que uno de los rasgos de la conceptualización del hemisferio occidental fue la integración de América a Occidente. Lo cual no era posible, para la conciencia criolla negra» (Op. cit., p. 88). Criollos hispanófilos, por ejemplo, priorizaron el referente europeo de constitución de nacionalidad; pero América no solo eran ellos y muchos nunca darían la espalda a los propios orígenes o a la hibridación de sus raíces.

El tercer periodo se asocia con esta misma reconfiguración geopolítica que supuso la pérdida de las últimas colonias hispánicas y, a partir de ahí, las nuevas relaciones de Estados Unidos con América Latina, que cobrarían un significado económico, político y militar en el marco de la guerra fría. Mignolo recuerda que aquí se «re-articuló en el imaginario del mundo moderno-colonial, la división entre el Atlántico Norte, protestante, anglo y blanco, y el Atlántico sur, católico, latino y no tan blanco ya» (Mignolo citado en Walsh, 2003, p. 5).

La misión modernizadora de esta etapa, de la mano de tesis como la del Destino Manifiesto, no solo buscó anexar territorios con un mero afán sumativo de posesiones, sino consolidar un proyecto occidental de política única (democracia liberal), economía única (centrada en el capital) y religión única (cristiana), en suma, la civilización de la paz, los derechos humanos, el progreso y el desarrollo, dando así nuevas caracterizaciones a la «matriz colonial del poder» bajo la impronta del bienestar de los pueblos.

Es el contexto expansionista en el cual la Doctrina Monroe, por ejemplo, aseguró para los Estados Unidos «el monopolio de los derechos de administración de la autonomía 
y democracia del hemisferio occidental» (Mignolo, 2011, p. 90). Así, se detectaban mecanismos de implementación de los principios de los estados-naciones imperiales para las balbucientes colonias emancipadas: «La Doctrina Monroe re-articulada con la idea de "hemisferio occidental" introdujo un cambio fundamental en la configuración del mundo moderno/colonial y en el imaginario de la modernidad/colonialidad» (Ibídem, p. 9o). Postura que, como queda dicho, acrecentó el ya considerable abismo entre la América Anglosajona y la América Latina, fijando los nuevos límites de «Occidente».

Sin embargo, la misión modernizadora de la colonialidad del poder no terminó allí. Tras las transformaciones sociales producto de la industrialización en el siglo XIX -donde también acunó el socialismo en el marco de las ideologías seculares modernas- y tras los ulteriores esfuerzos por consolidar una economía transnacional de mercado durante el siglo XX, se prepararon nuevas formas de colonialidad desde una suerte de procesos que combinan la hegemonía del hemisferio Occidental con el Atlántico Norte, es decir, Europa Occidental y Norteamérica9 .

La globalización contemporánea, en su versión unívoca y expansionista (colonialidad global), es el punto cénit de las manifestaciones anglo/eurocentristas, al punto que esa globalización, o mejor, según la precisión terminológica de Mignolo, el globalismo, en tanto proceso de estandarización económica y política, por la consolidación del capital transnacional, con sus consecuentes repercusiones socioculturales, fomenta la inequidad y promueve la violencia: La colonialidad más persistente es la derivada de la fase culmen del capitalismo global, la etapa del «mercado total» (Himkelammert, 2010) y la consecuente «desvalorización de la vida humana por el mercado total» (Mignolo citado en Walsh, 2003, p. 17). Ese globalismo, en las distintas formas de occidentalización, es el nuevo nombre de la colonialidad ${ }^{10}$.

9 En los términos de discusión que aquí se proponen, el énfasis se establece en la colonialidad como occidentalización. Las formas coloniales de la postoccidentalización, por la multiplicidad de acepciones que están tomando en la segunda década del siglo XXI, serían motivo de otro trabajo, pues, como bien apunta Mignolo, «postcolonialidad quiere decir nuevas formas de colonialidad y no su fin» (Mignolo, citado en Walsh, 2003, p. 15).

10 Mignolo (2010) y Escobar (2005), entre otros, han sustentado cómo la globalización aparece ligada a un proyecto clásico de colonialidad moderna amparado en la idea de «misión civilizadora», en cuya rearticulación han resultado útiles las ideas de «expansión de la democracia» 0 «desregulación de los mercados» o, más recientemente, «lucha contra el terrorismo». 
Ciertamente -y este es el punto que habría que destacar de esta rápida presentación de los grandes hitos-, la colonialidad global del poder es un fenómeno estructural prevaleciente. No es que se trate de momentos separados, claramente delimitados y ajenos unos de otros, aunque estén enmarcados por episodios puntuales. Por el contrario, el talante histórico-estructural de la colonialidad global se ha impuesto y se sigue imponiendo en la emergencia de las Américas, que no se consideran «occidente». Por eso, las etapas coexisten en «contradicciones diacrónicas» entre el periodo colonialista, propiamente dicho, el periodo nacional (división entre países «del Atlántico» y países «andinos» o «amerindios»; amén del establecimiento de las ideologías seculares liberal o socialista), y el periodo posnacional o globalista de la actualidad (Op. cit., p. 6). Ya hace unas décadas, Henri Grimal había advertido ese fenómeno amplio y complejo de la colonialidad más allá del colonialismo, legitimado por la dependencia económica transnacional:

La ruptura de los vínculos de dependencia, por muy importante que sea, sólo ha sido una de las etapas de la descolonización, y según algunos, la más fácil. La independencia política, para no ser una palabra vana, debe apoyarse en unas bases económicas sólidas. Numerosos estados en otro tiempo colonizados deben construir sobre bases nuevas una economía, hasta entonces orientada en función de las necesidades o de los beneficios del colonizador (Grimal, 1989, p. 408).

Ahora bien, como se ha sugerido ya, la colonialidad global del poder produce un sistema de diferencias imperiales/coloniales; es decir, supone una fijación de estamentos jerarquizados o «puntos de mira» desde los cuales opera en la consecución de sus propósitos o en la definición de la «necesidad colonialista $»^{11}$ : «La colonialidad del poder es el eje que organizó y organiza la diferencia colonial, la periferia como naturaleza» (Mignolo, 2011, p. 75). Podría hablarse, entonces, de la normalización de los márgenes como proyecto de sociedad ${ }^{12}$.

11 Se entiende por necesidad colonialista el proceso sostenido en la colonialidad global y sistémica del poder por el cual este se justifica como conveniente a partir de falacias o argucias doctrinarias que apoyan el sistema-mundo establecido, tales como «salvación eterna» (argumento religioso), progreso y desarrollo (argumento económico liberal), democracia y seguridad (argumento político), tecnificación y mercado (globalización neoliberal), entre otros.

12 La colonialidad del poder es la estructura que justifica la diferencia colonial. Se trata de un espectro epistémico que define los límites de la validación dentro de la producción y transformación 
En tal proyecto histórico, la diferencia colonial puede ser habitada de dos maneras: desde el territorio mismo que la ha creado, como un habitar segmentado explícito o inconsciente; desde este lado, la diferencia étnica, racial o patriarcal es connatural a la definición de sociedad, sin entender, ni siquiera percibir, la experiencia de lo distinto; la alteridad, en este caso, no es vinculante pues se desconoce la dinámica implicativa ante las formas identitarias del binomio modernidad/colonialidad. De otro lado, se halla la experiencia confrontadora del no-ser (colonial wound) que, al proceder de un territorio-otro, se asume en su distinción, como ejercicio de auto conciencia, dinamizando su propia producción de conocimiento y de participación (decolonial healing) (Mignolo, entrevistado por Argüello, 2013).

La perspectiva decolonial habla de los conocimientos subalternos como aquellos que, producto de la diferencia colonial, se consideran externos a la geopolítica oficial del conocimiento o, en el mejor de los casos, ponderados de acuerdo con ella. El testimonio de Mignolo al respecto, así lo confirma: "Cuando yo hablé de "subaltern knowledges", hablaba fundamentalmente que la colonialidad "subalterniza" todo conocimiento que no entra en los códigos de la modernidad. Entonces, Mariátegui [sería] subalterno» (Mignolo, entrevistado por Argüello, 2013b).

Por eso, la categoría de diferencia colonial conlleva otras como pensamiento fronterizo (border thinking) y desprendimiento (delinking), pues implica detectar e integrar la posición desde donde se produce y se legitima cada conocimiento, si desde la colonialidad del poder o desde la herida que esta produce ${ }^{13}$. En tal punto, la decolonialidad asume el escrutinio de las localizaciones geohistóricas que afrontan densos procesos de colonización y su emergencia a través de epistemologías de fronteras (Mattison, 2012).

Desde este presupuesto podría analizarse, por ejemplo, la configuración geopolítica basada en la comprensión del orden mundial, después de la Guerra Fría y la fuerza globalizadora, que marcan una redistribución de las civilizaciones y sus territorialidades, al estilo de S. Huntington. Sin embargo, en opinión de Mignolo, América Latina es una civilización en sí misma y ya no una parte del hemisferio occidental (Mignolo, 2011, p. 96). Ello es así tanto en razón de la diferencia imperial del continente (formas de ejercicio del poder por

de conocimientos y, más aún, en la configuración sociocultural y humana entre centros de poder y regiones subalternas o periferias.

13 Un mayor desarrollo de estos elementos desde la categoría propuesta por Mignolo de los lugares coloniales/decoloniales de enunciación se retomará más adelante, al comentar sus aplicaciones al plano de la educación. 
el colonialismo político-económico) como por la diferencia colonial que explicita la existencia de múltiples y variadas culturas autóctonas complejizadas por sus procesos de mestizaje.

Por eso, la reorganización del orden mundial desde un plano estamental y civilizatorio, según la propuesta de Huntington, tiene implicaciones en las relaciones internacionales, el orden económico-financiero del futuro, los movimientos migratorios y las políticas públicas, además de una renovada fase de repulsión racial alimentada por inusitadas xenofobias contra los «no-occidentales». Esta actualización de la colonialidad del poder se enmarca finalmente en la geopolítica de la economía pues «la diferencia colonial se redefine en las formas globales de colonialismo motivadas por las finanzas y el mercado, más que por la cristianización, la misión civilizadora, el destino manifiesto o el progreso y el desarrollo» (Op. cit., p. 99). Se afianza, entonces, el prototipo de la colonialidad global en términos de la colonización económico-política del planeta.

Es interesante resaltar cómo la redefinición de la diferencia imperial/colonial ya no procede, salvo contadas excepciones, en los términos de los Estados en sí mismos sino a través de sus corporaciones, sus alianzas transoceánicas, sus mecanismos de control, sus ideologías legitimadas etc. Existe hoy una desterritorialización de las colonialidades donde, ciertamente

el lugar no es un territorio, un Estado-nación imperial, como Inglaterra en el pasado, o Estados Unidos en la segunda mitad del siglo XX. El "lugar" no es un "territorio", sino un espacio de poder o, mejor, redes desde donde se ejerce la colonialidad del poder» (Mignolo citado en Walsh, 2003, p. 16).

Es así como la diferencia colonial se redefine en el interior de la civilización occidental o post-occidental desde las más activas dinámicas del poder, donde se incorporan ya no solo los factores raciales sino también, según se ha dicho, los políticos y económicos.

Una categoría más, para complementar el horizonte conceptual que se ha delineado hasta aquí, es el ya referido pensamiento de frontera (border thinking), el cual está relacionado con los conceptos precedentes de diferencia colonial y conocimientos subalternos.

El pensamiento de frontera es una concreción de los sistemas de intercomprensión pues no solo se concibe como emergencia del conocimiento sino también como proceso de interacción. De esta manera, se constituye a través de las categorías occidentales que le han negado legitimidad epistémica, como resistencia pero sin suponer la negación absoluta de las estructuras coloniales que lo rodean. 
En ese sentido, el pensamiento de frontera no es una entidad endógena, un producto de las comunidades particulares que revierte sobre ellas mismas, sino una actividad epistémica y social de interlocución entre historias locales y diseños globales. Este ejercicio de intercomprensión del conocimiento se asume como una actividad duradera de emancipación frente a las ideologías colonizadoras. Así lo plantea Mignolo al afirmar que «la decolonialidad abre las puertas de todos aquellos conocimientos que fueron subalternizados en nombre del cristianismo, del liberalismo y del marxismo» (Op. cit., p. 3). Hay aquí un potencial singular para develar los lugares coloniales de enunciación a partir de la experiencia de localidad, el desde dónde, es decir, la esfera de producción de sentido, desde la cual se comprenden los territorios epistémicos, éticos y políticos de enunciación.

Por ello, para la conformación del pensamiento decolonial/fronterizo es fundamental destacar que la enunciación está siempre localizada porque solo ahí se cifra un nodo simbólico-experiencial de memorias, relaciones, biografías y nuevas genealogías: «Las historias son siempre locales, cualquiera sea el imaginario y lo imaginado en esa localidad. Aunque sea la historia universal de Hegel, la "historia universal" es universal en el enunciado pero local en la enunciación» (Op. cit., p. 4) ${ }^{14}$. No es irrelevante recordar que «los lugares epistémicos del "paradigma otro" están en la historia del colonialismo desde la perspectiva de los actores que lo vivieron» (Mignolo, 2003, p. 22).

De esta forma, como se ha dicho, la emergencia del pensamiento de frontera depende de las historias locales y de la articulación particular con la colonialidad del poder, es decir, está marcado por la interculturalidad epistémica, social, ética, política, como ejercicio de «doble traducción».

Quien está en el territorio de la modernidad conoce el objeto epistémico de investigación. Desde esta lógica de las disciplinas, se puede ser un entendido en determinadas materias, pero ese conocimiento le sirve de poco a aquellos que han sido estudiados como «objetos». Para la decolonialidad, por el contrario, el conocimiento pertinente es aquel que se construye entre la frontera y la civilización occidental (en la manifestación de esta que corresponda); es un conocimiento en proceso de adaptación, de sobrevivencia, de lucha, más que una construcción de conceptos encerrada en sí misma (Mignolo, entrevistado por Argüello, 2013). La cuestión crucial de este proceso es, entonces, considerar cómo se vive y se

14 En el mismo sentido, Mignolo se ha referido en otro de sus trabajos a mostrar la importancia de «traer a primer plano las historias y centros negados a las periferias coloniales» (Mignolo, 20o9, p.179). 
piensa en la frontera ${ }^{15}$ de qué manera actúa el establecimiento social del border thinking: se trata de un «conocimiento adaptativo para... no son las disciplinas, el conocimiento es para avanzar en la liberación... crear espacios que la opresión no ha permitido. Ahí el conocimiento ya tiene otra función» (Mignolo, entrevistado por Argüello, 2013).

Es el mismo sentido de la disrupción epistémica a la cual convoca la decolonialidad: «pensar a partir y desde la diferencia colonial. No transformar la diferencia colonial en un 'objeto de estudio' estudiado (sic) desde la perspectiva epistémica de la modernidad, sino pensar desde el dolor de la diferencia colonial; desde el grito del sujeto, como diría Franz Hinkelammert y también lo textualizó Frantz Fanon» (Mignolo, 2003, p. 27).

Justamente ese potencial de las historias locales en diálogo con los vectores de colonialidad como presupuesto para la interculturalidad, en tanto «doble traducción», es plataforma constitutiva de la denominada hermenéutica pluritópica ${ }^{16}$ donde el encuentro de sistemas de conocimiento procura la rearticulación de la diferencia imperial y colonial, desde los cuales se desafían los diseños globales del mundo moderno-colonial (Mignolo citado en Walsh, 2003, p.7). Aquí se funda el itinerario hacia la diversidad como un proyecto pluralizable (por no decir universal) de mundo: «El desafío que esta doble traducción presenta a los participantes del proceso es el de lidiar y deshacer los lugares de poder asignados a los distintos tipos de conocimiento» (Mignolo, 2003, p. 21).

De esta manera, la configuración del border thinking opera entre interacciones, adaptaciones y resistencias, en suma, entre tensiones que en ningún momento procuran el control o la unilateralización, sino el posicionamiento activo, es decir, la imposibilidad de la anulación. El pensamiento de frontera implica la coexistencia de múltiples alternativas en emergencia y de proyectos coloniales -dado su carácter omniabarcante- pero resiste los intentos de jerarquización o dominio que pudieran establecerse de unos frente a otros porque se consideran una manifestación típica de la matriz colonial del poder:

15 Se entiende aquí que la frontera no es un lugar geofísico sino un entramado simbólico de experiencias de cautividad, marginación y negación.

16 En contraposición a la hermenéutica discursiva, de origen filosófico, cuya comprensión monotópica de inspiración moderna compacta la tradición que debe conocerse y los sujetos de conocimiento, «la semiosis colonial presupone más de una tradición y, por tanto, demanda una hermenéutica diatópica o pluritópica, un concepto que tomo en préstamo de Raimundo Panikkar» (Mignolo, 2009, p.182). 
Solamente dentro de un modelo evolutivo de la historia, el centro y la periferia pudieron ser fijados y ontologizados. Dentro de un modelo coevolutivo y de una hermenéutica pluritópica, los centros y las periferias coexisten en una lucha constante de poder, dominación y resistencia (Mignolo, 2009, p.179).

La idea de construir decolonialidad desde la lucha humana, pero también desde la interacción sistémica, es un punto central para comprender la dinámica que supera las visiones coloniales clásicas de sustitución de poderes centralizados, una de las características más visibles de las alternativas al capitalismo occidental formuladas desde el marxismo y sus derivaciones reducidas a transferencia de la concentración del poder.

En este contexto, la interculturalidad se convierte en el marco epistémico y social de la hermenéutica pluritópica. Pero no es la «interculturalidad oficial» de los aparatos ideológicos constituidos sobre los postulados de la colonialidad misma. No es el concepto atrapado en la retórica de la modernidad con semánticas de «inclusión» o «igualdad» a costa de identidad y participación. Como bien lo ha apuntado Mignolo, «la interculturalidad no es sólo el "estar" juntos sino el aceptar la diversidad del "ser" en sus necesidades, opiniones, deseos, conocimiento, perspectiva, etc.» (Mignolo, citado en Walsh, 2003,p. 8). Lo clave aquí es que el concepto de interculturalidad, desde un enfoque decolonial, revela y pone en juego la diferencia colonial, no la oculta o la diluye en una apuesta «bienintencionada» de igualdad normativa sin ejercicio público y social efectivo (Op. cit., p. 9) ${ }^{17}$.

Este elemento es crucial para comprender una interculturalidad decolonizada, el pensamiento de frontera y la hermenéutica pluritópica: los lugares de enunciación, múltiples en sus genealogías y sustratos, no son estandarizables ni jerarquizables, es

17 Significativo resulta referir en este punto la declaración de Mignolo en torno al proyecto de la decolonialidad como proceso de interculturalidad: «[La decolonialidad] es, primero, yo diría, afirmación de comunidades o de identidades que han sido devaluadas, ninguneadas, etc., sea la identidad homosexual, o indígena, etc. Segundo, es armarse como comunidades con la gente "de la misma piel"; y, luego, interactuar con la sociedad. Exactamente. Todo esto es lucha, de alguna manera, pero no hay que plantearlo como identidad que yo me aíslo y pongo bombas [...] Nosotros también estamos en la lucha, pero una lucha ética, política, epistémica, y ahí... si hay interacción es porque nosotros tenemos que estar muy firmes en lo que pensamos y en lo que hacemos, porque interacción como asimilación, ¡no! ¡nos tragan! [sic]. Ahí está el concepto indígena de interculturalidad. La interculturalidad es interacción. Nosotros queremos interactuar, no asimilarnos, participar en la construcción del Ecuador futuro, de la Bolivia futura, de la Colombia futura» (Mignolo, entrevistado por Argüello, 2013). 
decir, no se pueden suponer unos mejores que otros, o fijar derivaciones dependentistas, si no es a través de un interés colonizador explícito o mimetizado.

La interculturalidad decolonial, el reconocimiento del otro en su ser, implica confrontar las sinonimias falaces de integración auspiciadas por los modelos hegemónicos, o por las voces de aceptación tolerante pero sin implicación práctica en el reordenamiento de la historia colonial ${ }^{18}$. No es que se pretenda llegar a tomar las posiciones típicas de la colonialidad del poder o incentivar una aceptación pasiva de la diversidad en el panorama establecido $^{19}$. Por el contrario, la hermenéutica que se deriva del proyecto intercultural, en perspectiva decolonial, es un dispositivo epistémico de inevitable transformación social. De esta manera, «interculturalidad sería así un nombre de un fenómeno global cuyas características dependen de las historias locales y de la particular articulación de la colonialidad del poder en Asia, África y América Latina» (Op. cit., p. 11). Se recogen aquí destacados dinamismos de la sociedad contemporánea más allá de las discusiones categoriales asociadas a los modelos políticos decimonónicos. Por ello, Mignolo afirma que «el gran tema del siglo XXI será la doble traducción y la interculturalidad» (Op. cit., p. 7).

En resumen, todos los postulados estructurantes de la postura decolonial aquí comentados se pueden recoger en la idea de matriz colonial del poder, pues el carácter hegemónico de las geopolíticas del conocimiento no solo implica una definición epistemológica sino que se extiende al orden económico con la lógica del capitalismo avanzado y al político con la implantación de los Estados modernos nacionales, de donde se derivan las más variadas formas de la colonialidad en los distintos ámbitos de la vida humana y social. La colonialidad es una sistematización de la unilateralidad cuyos

18 Por eso el lenguaje de la inclusión no es inocente: «La inclusión nombra la generosidad desde la perspectiva del poder» (Mignolo, 2003, p. 34).

19 Comentado desde la experiencia de los pueblos originarios, «el proyecto "intercultural" en el discurso de los movimientos indígenas está diciendo otra cosa, está proponiendo una transformación. No están pidiendo el reconocimiento y la "inclusión" en un Estado que reproduce la ideología neoliberal y el colonialismo interno, sino que están reclamando la necesidad de que el Estado reconozca la diferencia colonial (ética, política y epistémica). Tampoco están pidiendo que se reconozca la participación de los indígenas en el Estado, sino la intervención en paridad y reconociendo la diferencia actual de poder, esto es, la diferencia colonial y la colonialidad del poder todavía existente, de los indígenas en la transformación del Estado, y, por cierto, de la educación, la economía, la ley» (Mignolo citado en Walsh, 2003, p.9). 
procesos de extensión son los encargados de asegurarla. En tal sentido, se afirma que «la colonización del tiempo ocurrió junto a la colonización del espacio» (Mignolo, 2012, p.13)

Se trata, entonces, de una estructura de regencia compleja o policéntrica que procura la colonización del ser en los distintos órdenes vitales. Como explicó el sociólogo peruano Aníbal Quijano (2011), la matriz es el sistema de dominación que extiende la colonización occidental-europea de las esferas políticas y económicas, y los sistemas de colonización del conocimiento, a los modus vivendi de las culturas, de manera que la colonialidad persiste como un dispositivo epistémico, ideológico y práctico de dominación (anglo-eurocentrista). Para Mignolo, esta omnipresencia histórica de la colonialidad es totalizante o cosmológica, al punto que «la cosmología occidental se ha hecho dominante y es muy poderosa» (Mignolo, entrevistado por Argüello, 2013).

Así pues, para concluir este apartado, los elementos sustantivos que definen la matriz colonial del poder pueden sintetizarse como sigue:

- Es histórica y transcronológica: puede ser identificable en etapas o acontecimientos específicos pero, además, sus fundamentos logran persistir en distintas modalidades, explícitas o tácitas, a lo largo de tiempos, condiciones y lugares.

- Es mimética, tiene la posibilidad de operar en nombre de ideas como «progreso» $\mathrm{y}$ «bienestar común» aunque no siempre conduzca efectivamente a la realización de sus contenidos. La retórica de la modernidad se ejerce encubierta de categorías aparentemente convenientes y deseables para todos; sin embargo, los discursos emancipadores en la oficialidad entrañan sutiles prácticas domesticadoras u opresivas en la realidad

- Posee ubicuidad estructural, es decir, alcanza -como el agua que se filtra- todos los planos posibles de la vida humana, personal y social, justamente en razón de una historia enquistada a lo largo de los siglos que ha procurado la colonización del ser y el control total de las subjetividades.

- Por lo anterior, es generadora de diferencias (diferencia colonial), crea periferias y reduce sectores enteros a la tercerización o al anulamiento aunque nunca logra una estandarización absoluta de los planos que controla frente al centro establecido.

20 Estas características establecen un estrecho sentido de afinidad con el proyecto moderno al punto que la colonialidad es el correlato práctico de la modernidad. 
- Se impone, explícita o tácitamente, como posición única sobre otras perspectivas que considera incompletas, erráticas o inadecuadas, haciendo prevalecer los «argumentos de autoridad», es decir, la validación de criterios por investidura funcional, histórica o institucional.

- Para los sujetos/estamentos hegemónicos, conlleva un elemento psíquico debido al miedo que produce perder el dominio propio de control (esfera de micropoderes) $\mathrm{y}$, ante esa pérdida, tener que resignificarse como nuevo actor en un paradigma conversacional-dialógico, lo cual fortalece el recurso a los argumentos de autoridad o de función mencionados en el punto anterior.

- Es resistente a las «minorías», consideradas como tal respecto de los núcleos hegemónicos y las ponderaciones estadísticas. De esta forma, protege la «falacia de las mayorías», es decir, la equivalencia entre sectores numéricamente dominantes con el sentido de prácticas canónicas y legitimidad social exclusiva (lo que hace, piensa, proyecta «la mayoría», es lo «correcto», lo «deseable», lo «conveniente»). Es una retórica para la normalización de lo común.

\section{El proyecto modernidad/colonialidad-decolonialidad y sus configuraciones en la educación}

\section{Educación y colonialidad}

Desde la perspectiva decolonial, el problema central que caracteriza la educación contemporánea en las sociedades emergentes, y que ocurre como expresión de la matriz colonial del poder, es la dificultad de definir en la práctica, no tanto en los documentos oficiales e institucionales, un telos pedagógico multimodal que exprese la complejidad de la condición humana y de los contextos socioculturales donde esta se desarrolla.

Sin pretender esbozar aquí la génesis de las falacias de la educación corporativa, desde sus discursos y prácticas oficiales dominantes, tanto en el sector público como en el privado, se pueden apreciar algunas formas de este relato monotópico en los principales colonialismos administrativos de la educación, donde destaca el absolutismo de la calidad, la empresarialización de los sistemas educativos, la estandarización fáctica de resultados comparativos, la laboralización de la enseñanza, la sectorización de destinarios 
benefactores y el desconocimiento de formas no-convencionales de las llamadas pedagogías-otras.

Las configuraciones de la colonialidad en la educación de las sociedades emergentes disuaden el hecho de que la pedagogía y, en general, todos los empeños de la educación, son, primordialmente, un acto de humanidad, de formación del espíritu humano, de viabilidad social y, desde ahí, de desarrollo sinérgico del mundo material ${ }^{21}$. Creer que se hace una «buena educación» solo porque se diligencian oportunamente los formatos de control, o porque se ocupan los primeros puestos en ciertos rankings, o porque se cumplen en rigor los manuales de procedimiento creados por pseudo-organismos pedagógicos, es una de las manifestaciones más comunes del relato monotópico contemporáneo.

Aquí radica el sentido de la «falacia desarrollista» (Dussel, 2003) en educación, la cual procura derivar de categorías de mercado, tales como calidad y competencias, propósitos sustantivos de humanización. La falacia consiste en hacer creer que quien opera pedagógicamente desde la calidad y las competencias, solo por sujeción canónica, logra ya todos los idearios educativos que la sociedad demanda ${ }^{22}$. Pero, desde las ancestrales tradiciones de la filosofía de la educación, así como desde los movimientos pedagógicos emergentes, no todos los propósitos de formación pueden configurarse como «competencias», aunque estas se denominen «socio-formativas». Las estructuras axiológicas, por ejemplo, por cuanto pertenecen al orden del ser, no se definen simplemente como resultado de una práctica factual acumulativa (en el orden del hacer) sino como constitución de identidades éticas (hábitos) sometidas al azar de la contingencia humana. Son ontológicas, por principio, antes que programáticas u operacionales.

De ahí que resulte posible afirmar que la colonialidad de la educación contemporánea se expresa, fundamentalmente, como una colonialidad de tipo económico-corporativo

21 Un referente del fundamento humano de la educación en esta perspectiva, se halla en el pensamiento pedagógico ancestral náhuatl llamado Huehuehtlahtolli o «Discursos de los ancianos» (León-Portilla, 2011).

22 En el caso de la política educativa del gobierno colombiano, por ejemplo, se encuentra una alusión, entre muchas otras, al sentido de calidad desde la «retórica de la modernidad», que se muestra como aliada natural de un discurso humanista: «La política educativa del Gobierno de la Prosperidad, se fundamenta en la convicción de que una educación de calidad es aquella que forma mejores seres humanos, ciudadanos con valores éticos, respetuosos de lo público, que ejercen los derechos humanos, cumplen con sus deberes y conviven en paz». Ministerio de Educación Nacional (MEN). 
y político-transnacional, esto es, una colonialidad del mercado y de las democracias modernizadoras.

En efecto, una educación dominada por el diseño global del «mercado total» acude a la fragmentación o al desplazamiento de sus teleologías éticas y sustantivamente humanas. La universidad moderna, por ejemplo, como fruto de una racionalidad univocista, alberga, por antonomasia, este reacomodo de los fines, pues, como ha apuntado Mignolo, la universidad-institución que prevaleció en las sociedades «occidentales» es producto de los diseños globales de la modernidad/colonialidad:

La expansión religiosa y económica de occidente fue paralela a la expansión de la universidad. En consecuencia, la situación de la universidad, en este plano, debe pensarse en relación a la distribución planetaria de las riquezas económicas. Pero, además, debe verse también en relación a la desvalorización de la educación en los diseños globales neoliberales, paralelos a la desvalorización de la vida humana (Mignolo citado en Walsh, 2003, p.19).

Más exactamente habría que referir una desvalorización intencionada de ciertos idearios, el ético-humanista, para privilegiar otros, los del mercado puro, aunque ello no implique la anulación de facto de postulados como la «formación integral», «el compromiso ciudadano», «el desarrollo social», entre otros. De hecho, la colonialidad de las pedagogías se manifiesta especialmente en las nuevas retóricas de la modernidad, cuya mejor herramienta es la estrategia del discurso mimético, esa habilidad táctica de la dualidad que normaliza, por necesidad individual o por interés colectivo, visiones particulares como universalmente deseables.

Así pues, las formas sistémicas de colonialidad en la educación, establecidas, como se ha dicho, por el dictatus economicus de la modernidad, se sintetizan en dos dominios que resultan fundamentales de toda acción humana: el de los lenguajes ${ }^{23}$ y el de las axiologías o esquemas valorativos de significación ${ }^{24}$.

23 Como se ha insinuado a lo largo de este trabajo, una de las formas más claras de visibilización de la colonialidad del lenguaje pedagógico es el univocismo en torno a la comprensión del ser educativo, es decir, la unidimensionalización de las teleologías, definidas, en instancia prioritaria, por vía económico-corporativa a través de los discursos empresariales de la excelencia, la alta calidad, la prosperidad, la acreditación, las competencias, etc.

24 Un trazo de los principales colonialismos epistémicos de la educación formal puede encontrarse en el comentario de Mignolo, dentro del proyecto expansionista de la universidad 
Desde esta perspectiva, los proyectos educativos instalados y controlados por los sistemas formales actúan como extensiones matriciales, esto es, como aplicaciones locales de diseños con pretensión universal que procuran asegurar la reproducción de la colonialidad. Lenguajes y axiologías no actúan aquí como campos inconexos sino como territorios epistémicos que, en el enfoque decolonial, se denominan lugares de enunciación (locus enuntiationis).

El escrutinio del lugar de enunciación contribuye a desvelar los emplazamientos de la colonialidad, o, lo que es lo mismo, las epistemologías del poder. No se trata solo del nivel descriptivo en torno al quién lo dice, sino del plano hermenéutico-crítico del por qué (causas), para qué (finalidades) y desde dónde (posicionamientos) se dice, esto es, desde qué estructura de significación se desenvuelve la existencia, se elaboran categorías, se enuncian juicios, se legitiman relatos para comprender el mundo, los sujetos y sus relaciones.

Someter a examen el locus de enunciación significa, pues, esclarecer cómo se han pensado y determinado las formaciones discursivas, los usos de las lenguas, las concepciones culturales, en suma, detenerse en «las condiciones de posibilidad para la creación de espacios-en-medio como una forma diferente de pensar» (Mignolo, 2009, p.172) ${ }^{25}$.

La colonialidad axiológica de la educación y del lenguaje pedagógico actúa aquí como dispositivo de control desde la extensión matricial. Es un diseño global (a)propiado,

moderna: «Los principales puntos de articulación del imaginario construido como "hemisferio occidental" son: etno-racialidad, aspectos de clases y aspectos de género y de sexualidad» (Mignolo, 2011). Sobre estos ejes argumentales se definen los criterios civilizatorios a lo cuales debe servir la educación.

25 Es común que ante las hegemonías de la Modernidad se opongan hitos pseudoemancipadores. Para la escuela decolonial, por ejemplo, existe una especie de autosuficiencia explicativa de la posmodernidad, porque como parte de un mismo sistema de pensamiento, contiene la fuerza metamorfoseada del mismo proyecto moderno: «La posmodernidad, autoconcebida en la línea unilateral de la historia del mundo moderno continúa ocultando la colonialidad, y mantiene la lógica universal y monotópica - desde la izquierda y desde la derecha - desde Europa (o el Atlántico Norte) hacia fuera» (Mignolo, 2011, p.76). Aquí se observa también el problema de los «lugares de enunciación» y la necesidad de su desciframiento, es decir, de desvelar la perspectiva desde dónde se piensa al otro; y, en consecuencia, la manera de definirse a sí mismo, evitando en todo caso el riesgo de la teorización excesiva de la otredad. Por lo tanto, si Europa piensa a América o África como el lugar del bárbaro, se autoconcibe como «señor de los incivilizados», autorizándose para una colonialidad que considera legítima. 
hecho propio sin serlo, por necesidad social. De esta forma opera, a través de la educación canónica, la programación calculada de la existencia de individuos, pueblos y colectivos. Acaece la constitución colonial de los saberes, lenguajes y memorias desde el lugar de enunciación asociado al poder imperial (Mignolo, 2009), es decir, la construcción intencionada de el otro y de lo otro sobre una fuerza legitimadora de las soberanías fundadas en ideales de progreso y civilidad universal, antecedente de una modernidad anglo/eurocéntrica reciclada que justifica la exclusión de los sectores que no ingresan en ese patrón de identidad colectiva.

Este modelo de educación (corporativa) se configura desde la colonialidad del saber, por el tipo de conocimiento que se estima necesario y transmitible, y, desde la colonialidad del ser, por los modos de identidades que se avalan y se normalizan. De ahí la importancia de fragmentar los esquemas monotópicos para apreciar la reemergencia de las fronteras, es decir, los mundos-otros, las pedagogías-otras, los conocimientos locales necesarios, los patrimonios intangibles y las múltiples formas constitutivas de los procesos humanos de la educación.

\section{La apuesta por pedagogías decoloniales en las sociedades emergentes}

Según lo expuesto, la propuesta de la educación decolonial se estructura a partir de dos vectores sustantivos: el papel de sujetos e instituciones frente a la colonialidad del ser (identidad) y del saber (conocimiento); y, la función renovada de estos en una sociedad decolonizada.

Ambas vertientes se recogen en la reflexión de Mignolo al conjugar el sentido de lucha e interacción típico de las dinámicas decoloniales:

[La decolonialidad] es, primero -yo diría- afirmación de comunidades o de identidades que han sido devaluadas, ninguneadas, etc., sea la identidad homosexual, o indígena, etc. Segundo, es armarse como comunidades con la gente de la misma piel; y, luego, interactuar con la sociedad. Exactamente. Todo esto es lucha, de alguna manera, pero no hay que plantearlo como identidad que yo me aíslo y pongo bombas (...); nosotros también estamos en la lucha, pero una lucha ética, política, epistémica, y ahí... si hay interacción es porque nosotros tenemos que estar muy firmes en lo que pensamos y en lo que hacemos, porque interacción como asimilación, no. Nos tragan (sic). Ahí está el concepto indígena 
de interculturalidad. La interculturalidad es interacción. Nosotros queremos interactuar, no asimilarnos, participar en la construcción del Ecuador futuro, de la Bolivia futura, de la Colombia futura. (Mignolo, entrevistado por Argüello, 2013).

Se trata del doble dinamismo de la pedagogía decolonial que se ilustra a continuación.

El papel crítico de sujetos e instituciones frente a la colonialidad del ser (identidad) y del saber (conocimiento)

Uno de los aspectos centrales de la perspectiva decolonial es la necesidad de cuestionar un «todo unificado» de ser humano, de configuración social, de producción e interpretación cultural heredado de una modernidad absolutizante. De ahí se deriva el florecimiento de múltiples humanidades o, dicho de otro modo, el restablecimiento del sujeto emergente decolonial.

$\mathrm{Al}$ reconocer, como se ha indicado anteriormente, los impactos de la globalidad en la educación, en especial, los de tipo socioeconómico y político-cultural, es preciso recuperar el papel de la educación en la conformación de nuevas subjetividades e institucionalizaciones de lo social para alentar, así, un proceso continuo de resistencia creativa al colonialismo, en cualquiera de sus manifestaciones. En otras palabras, la pedagogía decolonial no aparece tanto como un dispositivo de reproducción, sino más bien, de búsqueda, afianzamiento e interlocución de posibilidades creadoras.

Es el punto que también Mignolo ha señalado al comentar el papel de las instituciones universitarias en la geopolítica del conocimiento, pues, «hay historias locales en las que se piensan y distribuyen diseños globales y otras historias locales que sólo tienen la opción de negociar con tales diseños globales [...]. Lo que nos interesa aquí es la configuración de la diferencia colonial en el plano institucional de la educación» (Mignolo, citado en Walsh, 2003, p. 20).

De este modo, el proceso de constitución y florecimiento de todas las subjetividades posibles en una sociedad, preparado, auspiciado y desarrollado por la acción educativa, procurará que todos los seres humanos de una comunidad dada puedan ser quienes realmente son. Pero, para contribuir a un escenario público donde cada otro sea quien es, resulta fundamental la educación para el pensamiento crítico decolonial que compromete no solo al sujeto que se restablece, desde la negación, en el entramado democrático, sino también al que debe restablecerse desde su situación de hegemonía. 
La cuestión es la educación para la descolonización del ser. Darle a los individuos, a las personas, los instrumentos necesarios para que entiendan lo que está pasando hoy desde la perspectiva de la colonialidad. Eso es. Nada más y nada menos (...). Ir pensando y haciendo entre todos un tipo de educación que es des-colonizadora. Primero del ser. Porque no puedes descolonizar la economía si tienes un ser que ha estado formado por la Modernidad. (Mignolo, entrevistado por Argüello, 2013b).

El pensamiento crítico es, pues, la capacidad de escrutar los lugares de enunciación colonial, identificar las retóricas de la modernidad, reflexionar sobre las prácticas de sí y acompañar las agencias requeridas para «cicatrizar» las heridas de la colonialidad. Por eso, frente a los lugares de dominación del ser y del saber, no es posible la afirmación de conocimientos e identidades-otras sin el ejercicio epistémico y experiencial de la criticidad.

El objetivo de la educación decolonial: decolonizar el conocimiento y decolonizar el ser [...]. En la base del análisis de la colonialidad, el objetivo es que el estudiante se dé cuenta dónde está y se decolonice descolonizando los conocimientos; y descolonizando los conocimientos, quiere decir que ya no cree en lo que le dice la televisión colombiana, los diarios y el discurso del presidente, sino que está constantemente analizando en esos discursos qué oculta la retórica de la modernidad (...). Yo le digo a los estudiantes: «Fíjense en lo que pasa alrededor de ustedes y vean cómo opera la colonialidad» y uff (sic), empiezan. ¡Y cuando lo empiezan a ver no paran más! La ven por todo lado. Una vez que la ves, la ves por toda parte (Mignolo, entrevistado por Argüello, 2013b).

En sentido similar, al referirse al papel de las disciplinas y la actividad académica, el pensador argentino comenta:

La tarea intelectual del académico (a) es producir pensamiento crítico[...]. El pensamiento crítico tendrá que ser desde la colonialidad, por la descolonización tanto económica como intelectual, tanto de derecha como de izquierda [...]. El pensamiento crítico en la sociedad global deberá ser un constante proceso de descolonización intelectual que deberá contribuir a la descolonización en otras áreas: ética, económica y política (Mignolo, citado en Walsh, 2003, p.22). 
Tanto en los análisis de realidad como en la confrontación de las disciplinas, ningún pensamiento crítico decolonial es de alcance particular o individualizante. Dado que el giro decolonial sustenta un proyecto histórico fundado en el desprendimiento y la apertura para la coexistencia constructiva, se hace necesario fundar en el sujeto una agencia decisoria ante múltiples opciones cuyo impacto rebasa la esfera del individuo. El pensamiento crítico en la pedagogía decolonial tiene, en última instancia, una función de posicionamiento de la diversidad que no pretende coartar sino discernir para su lugar social:

Pedagogías que animan el pensar desde y con genealogías, racionalidades, conocimientos, prácticas y sistemas civilizatorios y de vivir distinto. Pedagogías que incitan posibilidades de estar, ser, sentir, existir, hacer, pensar, mirar, escuchar y saber de otro modo, pedagogías enrumbadas hacia y ancladas en procesos y proyectos de carácter, horizonte e intento decolonial (Walsh, 2013, p. 28).

En este punto, la pedagogía decolonial aparece como una forma singular de educación intercultural cuya clave es hacer viable la diferencia de perspectiva frente a otras propuestas de ser y de pensar:

Los campesinos, los indios, los negros... están tomando los instrumentos y construyendo. Este es el momento decolonial. Los sujetos crean sus diseños, crean su conocimiento y lo utilizan de acuerdo a sus necesidades, que es un conocimiento adaptativo para esa interacción porque no podés interactuar si no tenés (sic) bien fundamentados tus conocimientos. Ya es más difícil la asimilación, hay tensión pero ya no hay vuelta atrás (...) Este es el momento decolonial de todo, de la educación, del arte, del conocimiento (Mignolo, entrevistado por Argüello, 2013).

Es el aspecto del posicionamiento de sujetos e instituciones emergentes que se desarrolla en el segundo elemento de este apartado. 


\section{Función renovada de sujetos e instituciones emergentes en una sociedad decolonizada}

Junto al restablecimiento o emergencia de (nuevas) subjetividades ocurre el posicionamiento del ser en lo social. Desde el ejercicio del pensamiento crítico, la decolonización del ser conduce a la decolonización política, pues sin la afirmación previa de saberes-otros e identidades-otras tampoco es posible la redefinición de coexistencias en una «democracia decolonial». De ahí que el trasfondo político de las pedagogías decoloniales enfatice el sentido de la educación como tarea social y su responsabilidad en la (re)construcción de lo público. La pedagogía se entendería, entonces, como:

[el] proceso accional, típicamente llevado de manera colectiva y no individual, [que] suscita reflexiones y enseñanzas sobre la situación/condición colonial misma y el proyecto inacabado de la des- o de- colonización, a la vez que engendran atención a las prácticas políticas, epistémicas, vivenciales y existenciales que luchan por transformar los patrones de poder y los principios sobre los cuales el conocimiento, la humanidad y la existencia misma han sido circunscritos, controlados y subyugados (Walsh, 2013, p. 29).

Singular importancia tiene aquí la pluriversalidad (o interculturalidad decolonial) como el espectro epistémico y social producto del florecimiento de múltiples conocimientos e identidades que transforman los modos de subjetivación, las configuraciones arquetípicas de la organización política y las formas de ser en la esfera pública.

La primera consecuencia de ello es la revisión de los postulados que definen tradicionalmente al Estado Moderno como norma común de la política occidental, pues «la identificación de la ciudadanía con un solo patrón de conducta oficializada por el EstadoNación, restringe sensiblemente el reconocimiento de otras identidades ciudadanas que se forjan al calor de sus ancestrales formas de cultura e historia» (Márquez-Fernández, 2012, p.92). Por eso, la perspectiva decolonial cuestiona el modelo político del Estado Moderno, pues, aunque cuente con reelaboraciones conceptuales inclusivas, no favorece en la práctica concreta la alteridad coimplicativa, ni la pluralidad de las identidades ciudadanas requeridas por la interculturalidad. Por eso, al parecer de los teóricos de la perspectiva, es menester vigilar la semántica del conocido término: 
Cuando la palabra «interculturalidad» la emplea el Estado, en el discurso oficial, el sentido es equivalente a «multiculturalidad». El Estado quiere ser inclusivo, reformador, para mantener la ideología neoliberal y la primacía del mercado. Pero, en todo caso, es importante reconocer las reformas que se pueden realizar a través de la política del Estado. En cambio el proyecto «intercultural» en el discurso de los movimientos indígenas está diciendo otra cosa, está proponiendo una transformación. No están pidiendo el reconocimiento y la «inclusión» en un Estado que reproduce la ideología neoliberal y el colonialismo interno, sino que están reclamando la necesidad de que el Estado reconozca la diferencia colonial (ética, política y epistémica). Tampoco están pidiendo que se reconozca la participación de los indígenas en el Estado, sino la intervención en paridad y reconociendo la diferencia actual de poder, esto es, la diferencia colonial y la colonialidad del poder todavía existente de los indígenas en la transformación del Estado, y por cierto, de la educación, la economía, la ley (Mignolo citado en Walsh, 2003, p.9).

De esta forma se hace patente el desafío de abrir las comprensiones sobre sociedad, política, economía, educación, etc., según las múltiples conformaciones culturales que coexisten en determinado espacio vital, sin confundir legitimidad ciudadana con mayoría estadística poblacional, técnica proclive al anulamiento de sectores emergentes. Por eso los relatos de la «ciudadanía oficial» pueden resultar una sutil dominación/apropiación que se traduce en los intentos de construir, en las periferias biogeográficas, versiones asemejadas de una modernidad angloamericana o europea.

En términos de ejercicio del poder, se contiene aquí un inevitable desplazamiento paradigmático que resiste toda modalidad, explícita o velada, de gobernabilidad imperial, absolutista y plegada sobre el propio arbitrio del tirano (dictadura) o del partido (partidocracia): «El énfasis sobre una concepción anti-hegemónica del poder de la política, es una cuestión que pasa por la crítica al uso totalitario, populista, colonial, del poder para gobernar» (Márquez -Fernández, 2012, p.91). La democracia misma debe revisar sus formas inconclusas para permitir una versión transliberal que, preservando lo mejor del ideario de la emancipación ilustrada, convoque la perspectiva de la Tierra y los territorios, de los múltiples mundos.

En el planteamiento decolonial, la política se entiende como «espacio público de reconocimiento del otro», el escenario legal pero, sobre todo ético, donde cada individuo y cada colectivo pueda ser quien efectivamente es. La reconversión de la mirada política ya no tiene por centro las estructuras del sistema en sí mismas, como entidades aisladas, sino 
el movimiento intrínseco de las comunidades, el dinamismo no-estandarizado, por ende, contingente, de los colectivos donde cobran vida los mitos, las tradiciones, los constructos simbólicos: «El espacio público se ha desterritorializado por la emergencia de movimientos sociales que irrumpen en la estructura de los controles sociales, desde el más institucional hasta el más mediático» (Op. cit., pp. 92-93). Es el momento, como ha manifestado A. Escobar (2012), en que los movimientos sociales se tornan sociedades en movimiento, mundos que se levantan, mundos relacionales hacia un nuevo proyecto civilizatorio.

De esta forma, tales movimientos y las naciones emergentes que constituyen, actúan como fuerzas desmovilizadoras de los mecanismos de control y de poder político concentrado. En ellos se confrontan los caducos modelos unilaterales de gobierno y se prepara, por desplazamiento progresivo de paradigmas, la pluriversalidad como nueva forma democrática del Estado, ahora pluriétnico, multilingüe y pluricultural. La política decolonial expresa así el proceso de desequilibrio en el sistema de poder del estado-nación (Ibídem, p.93) ${ }^{26}$.

De esta forma, el plano político de la pluriversalidad contiene el desafío de construir una comunidad ética global, sin estandarizaciones, pero también, sin insularidades, pues ambos polos niegan el ejercicio intercultural crítico. Desde el punto de vista educativo, se destacan al menos dos tareas para esta dinamización de las sociedades emergentes en la esfera política. Por un lado, contribuir a la repolitización del Estado nación hacia un Estado definido en la práctica por la pluralidad de lo diverso en sus actores, tradiciones y agencias. Y, por otra parte, afianzar los derechos de participación de toda la comunidad civil en orden a la configuración sistémica de la política fundada en la diversidad coimplicativa.

Esta manera de comprender los modelos políticos se relaciona con las concepciones alternativas del Estado que, a su vez, brotan de la sociología de emergencias, a saber: la plurinacionalidad, la democracia participativa integral, las concepciones de desarrollo como buen vivir (Sumak Kawsay) y no como sinónimo creciente de rentabilidad, y una noción amplia e integradora de los derechos humanos que incluye derechos de los animales y derechos de la naturaleza en general (De Sousa, 2011, p.18).

26 La reconfiguración del plano político en clave decolonial también debe ir más allá de las formas elaboradas de los partidos políticos. No es un legado ni de «izquierdas» ni de «derechas» pues ambos polos son capaces de ejercer la colonialidad. Es más un planteamiento de principios e intereses para una civilización biocentrada: «Repensar quiere decir desprender la lógica de las independencias decolonizadoras de las revoluciones burguesas y socialistas» (Mignolo, 2009b, p. 664). 
La plurinacionalidad, como forma adecuada del Estado en la gestión de la pluriversalidad, demanda la interexistencia y la intercomunidad, o sea el fundamento sobre un principio intercultural práctico y no solo multicultural técnico. Lo ideal no es propugnar únicamente la nación cívica (que acoge el modelo del «buen ciudadano»), sino también la nación étnico-cultural, que no excluye a quienes no se integran al modelo cívico-moderno ${ }^{27}$. Se trata, entonces, de una política definida por la complementariedad de la democratización social y las formulaciones estatales de nación.

La reconversión política sobre cómo «lo decolonial» no es sólo enfrentarse sino integrar «lo colonial» con mirada alternativa, al menos no reproduccionista, es comentada por Mignolo, en los siguientes términos:

Re-surgir, Re-emerger, Re-existir. Quiere decir que nos habían apabullado y nosotros nos creímos que éramos inferiores. No más. [Las sociedades emergentes] están ahora apoderándose de todos los instrumentos occidentales del conocimiento para entrar en el debate de la esfera pública, y esto no se puede parar ya. No sé qué efecto tendrá, pero ya no se detiene. (...) Es decir, los diseños globales son de occidente pero ahora ya no pueden ser ejecutados con la holgura con que lo fueron hasta el 2000 más o menos (China, Rusia, el Islam, etc.)...

Para esto nos sirve la matriz colonial del poder. Lo que decimos nosotros [los intelectuales decoloniales], es que la matriz colonial del poder la inventó, la formó, la armó, la controló, Occidente: España, Francia, Inglaterra, Estados Unidos. Ahora ya no la puede controlar, porque China y los BRIC's e Indonesia y Turquía están disputando el control de esa matriz y por eso es en parte la crisis que tenemos. Porque esa disputa es política pero también es económica, o sea, Europa y Estados Unidos ya no pueden «comerse todas las tortas del mundo». Hay otros comensales. Estados Unidos ya no puede tomar decisiones políticas por sí solo. Por eso Rusia paró a Obama en Siria. Esa fue una jugada magistral. Eso no es decolonización, yo llamo a eso des-occidentalización. Pero esto quiere decir que la necesidad de reemerger es la misma (Mignolo, entrevistado por Argüello, 2013).

27 Una forma de Estado que se define desde una ciudadanía oficial es proclive al denominado «fascismo social», que se caracteriza por «la combinación de la exclusión social y política por la cual se produce el incremento de largos sectores de la población viviendo bajo terribles condiciones materiales y a menudo bajo la amenaza de desplazamiento o incluso de muerte» (Escobar, 2005, p. 32). 
El presupuesto de la cosmovisión política decolonial sobre el florecimiento de múltiples saberes e identidades que produce un nuevo sistema «democrático»y, en consecuencia, la necesidad de que el «mundo real» de las corporaciones coexista y construya con el otro «mundo real» de las sociedades emergentes -no uno a costa de otro-, supone una tarea de desciframiento que exige aprehender, diseccionar y recomponer los relatos miméticos de la oficialidad (pensamiento crítico), desde un ejercicio de reconstrucción social y humana impulsado por la educación. Es el principio de la pedagogía decolonial como educación plural.

\section{El pacto pedagógico decolonial}

Como se ha comentado en el apartado El papel crítico de sujetos e instituciones frente a la colonialidad del ser (identidad) y del saber (conocimiento), los modelos educativos dominantes han planteado de una y otra forma la insistencia de una educación para la competitividad, la eficacia y la generación de lucro que respondan a los cambios introducidos por la «revolución tecnológica» (Mignolo, 2003, p. 46). En la pedagogía global, se hace explícita una mirada reduccionista de la educación como preparación para el trabajo y, particularmente, para la asimilación, en este caso, de las lógicas convencionales del homo economicus. Pero la idea de la educación como tarea social en la reconfiguración del universo humano y planetario, antes que someterse ciegamente a los grandes sistemas económicos y políticos transnacionales, se asume integrada a los (nuevos) imperativos éticos del siglo XXI. La decolonialidad es una forma de interactuar para desmontar la retórica contemporánea de la modernidad, la de las corporaciones y la de los organismos educativos que funcionan según las ideologías transnacionales, en disposición de apertura a la complejidad constitutiva de lo vital.

Por ello, decolonizar la plataforma imperial/colonial de la «educación para el rendimiento» parte de un retorno a «lo humano de lo humano» (Morin), es decir, una ética contemporánea, que se pretenda realmente vinculante de la experiencia humana actual, debe romper la lógica fragmentaria de las plataformas colonialistas que escinden naturaleza-cultura, razón-emoción, orden-caos. El punto central es el establecimiento de un pacto ético de las diferencias, que asegure no solo la convivencia tolerante sino la interacción continua de lo distinto: «Una ética global y un conocimiento y política decolonial deben centrarse fuera de las tradiciones occidentales aunque las considere para comunicarse con ellas y para incluirlas» (De Lissovoy, 2010, p. 283). 
El escenario pluriversal que afrontan las pedagogías decoloniales demanda, pues, un sentido particular de pacto ético antes que una huida, una negación o una confrontación ingenua del lugar de dominación. Para plantearlo con claridad, de cara a los desarrollos posteriores, la pedagogía decolonial no pretende una resistencia obtusa al proyecto de la educación corporativa en sí mismo, sino a sus arrebatos imperiales de universalidad y totalidad: «La coexistencia significa la hodierna re-inscripción de las organizaciones económicas no-capitalistas y de los conocimientos no-modernos que han co-existido con el capitalismo, pero que han sido marginalizados o incorporados a la mentalidad capitalista» (Mattison, 2012).

La pregunta, entonces, es cómo establecer las conversaciones necesarias entre la geopolítica del conocimiento y del poder, y la rearticulación de la diferencia imperial/ colonial; entre la retórica de la modernidad junto a la lógica de la colonialidad y el «pensamiento de frontera». En otras palabras, el punto nodal es cómo alcanzar conversaciones y cooperaciones con otros proyectos de pensamiento, tramas de identidades y sistemas de conocimiento de modo que la posición desde donde se produzca el saber y se definan las identidades no evoque solo el plano del dominador sino también el lugar de la «herida colonial»y el significado de habitar en la periferia epistémica y social ${ }^{28}$.

El primer paso del desprendimiento decolonial (decolonial delinking) es re-inscribir en los debates contemporáneos y con visión de futuro, organizaciones sociales y concepciones económicas que fueron borradas y silenciadas por el discurso progresivo de la modernidad,

28 En el ámbito de las discusiones intelectuales para la construcción del conocimiento, la apuesta por un «pacto decolonial» conlleva el ejercicio de la desmitificación de las fuentes. Al respecto Mignolo ha señalado el desafío de «dejar de pensar que lo que vale como conocimiento está en ciertas lenguas y viene de ciertos lugares. Y dejar así de pensar que los zapatistas han estado produciendo una revolución teórica, política y ética. De modo que si, por ejemplo, para entender a los zapatistas me baso en Bourdieu o en los métodos sociológicos, pues, lo que hago es reproducir la colonización del conocimiento negando la posibilidad de que para la situación histórico-social en América Latina, el pensamiento que generan los zapatistas sea más relevante que el que produce Jürgen Habermas. Una de las consecuencias negativas de la geopolítica del conocimiento es impedir que el conocimiento se genere de otras fuentes, que beba en otras aguas [...]. Otra consecuencia de la geopolítica del conocimiento es que se publican y traducen precisamente aquellos nombres cuyos trabajos "contienen" y reproducen el conocimiento geopolíticamente marcado [...]. ¿Cuántos en América Latina tomarían a Frantz Fanon como líder intelectual en vez de Jacques Derrida y Jürgen Habermas?» (Mignolo, citado en Walsh, 2003, pp. 3-4). 
tanto en su modalidad de capitalismo liberal como de comunismo socialista [...] No hay un modelo matriz de coexistencia: ella se inscribe en todas las memorias no-modernas que, desde 1500, han sido puestas a un lado y situadas en el pasado en relación a las ideas occidentales de la Modernidad (Mattison, 2012).

En tal punto, la negociación intercultural es el mecanismo que impide la unilateralización de los discursos empresariales o, en general, de las lógicas unidimensionales en la educación, lo cual implica el trabajo cotidiano de la diferencia colonial a través de prácticas sociales alternativas y la reformulación de las hegemonías (border doing); es decir, se trata de acordar los «diferentes grados y niveles de interferencia e hibridación» (Mignolo, 2009, p.181) que hacen posible incidir en la dialéctica historias locales-diseños globales ${ }^{29}$.

Así, el pacto pedagógico decolonial se estructura sobre la idea de pluriversalidad sin excluir la posición antagónica. Exige transitar del monólogo del pensamiento de la modernidad europea al polílogo decolonial para diseñar futuros posibles: «Es un pensamiento diatópico o pluritópico enfrentado, en conflicto, con las ideologías monotópicas de la modernidad» (Mignolo, 2003, p. 52). La postura decolonial no ve a la modernidad como un enemigo insalvable, más bien, considera que el pensamiento fronterizo, para consolidarse como tal, precisa interactuar con ella. Es el interlocutor omnipresente. Al fin y al cabo, colonizado y colonizador siempre están articulados, pero hay que trabajar para estarlo de otro modo:

Una educación hacia la pluriversalidad es una educación decolonial donde el estudiante tiene que entender que, digamos... el mundo del futuro difícilmente puede estar ya controlado por una universalidad. Y la pluriversalidad quiere decir que hay muchas universalidades. Es decir, aceptar «la universalidad», entre paréntesis. Pluriversalidad

29 Según se ha señalado al referir el talante decolonial de la interculturalidad, la hermenéutica pluritópica recoge la idea de traducción intercultural en tanto comunicación de prácticas subalternas para «propiciar el mutuo entendimiento e inteligibilidad entre los movimientos que confluyen en las redes, pero con cosmovisiones, mundos-vida y concepciones que son a menudo diferentes y extrañas entre sí, si no plenamente inconmensurables» (Escobar, 2005, p. 43). Para realizar ese ejercicio conversacional, se requiere comprensión y negociación de significados, tal como sugiere De Sousa: «La traducción es el proceso que permite la inteligibilidad mutua entre las experiencias del mundo (...). El ejercicio de traducción apunta a identificar y potenciar lo que es común en la diversidad de la ruta contra-hegemónica» (De Sousa, 2003, p. 341). 
es la coexistencia, la articulación, digamos, del planteamiento en China, el Islam, etc. y la modernidad reducida a su justo medio. [La modernidad] es una propuesta más. Exactamente. Y la diferencia es que la modernidad fue la primera civilización que se articuló en todo el mundo. Entonces todo el mundo ahora se conecta a través de la modernidad. [...] Lo pluriversal es el horizonte donde mucha gente tiene que contribuir. Entonces lo que el estudiante tiene que aprender ahí, de una pedagogía decolonial es que ya no se puede pensar en universales, a no ser que se apoye el imperialismo (énfasis del entrevistador) (Mignolo, entrevistado por Argüello, 2013b).

De esta forma, como se ha explicado previamente, la pedagogía decolonial integra una tarea de posicionamiento político de los sujetos/colectivos emergentes que incumbe directamente al contrato intercultural: «Para mí es muy importante también darle a los jóvenes un mapa de lo que está pasando, que ya no estamos en el mundo del siglo XIX o siglo XX. Estamos en un orden global donde hay fuerzas» (Mignolo, entrevistado por Argüello, 2013b). La decolonialidad apuesta por intervenir en la esfera pública, pues no es solo un discurso para la expresión o protección endógena de la diversidad. Si bien, como apuntaba el filósofo Ortega y Gasset en su conocida máxima, las circunstancias son parte del Yo, no se permanece en ellas de modo impasible sino que estas se confrontan, se desplazan y se cambian. El determinismo histórico no es compatible con la decolonialidad porque el sujeto decolonial no es un sujeto de la observación pasiva, sino de la actuación. Quien elige esta perspectiva no opera como un arqueólogo, cuyo centro de atención son los vestigios del pasado, sino que procura la intervención en el presente, la reconducción de la historia, de su historia. Por eso, el pacto ético decolonial está conectado con un nuevo sentido de lo público -en la línea expuesta anteriormente-, a propósito de reconstituir los actores emergentes como comunidad y propiciar, en voluntad de concordia, un andamiaje de participación e interacción vinculante.

\section{Conclusión: Hacia una didáctica de la decolonialidad}

No existe un procedimiento algorítmico para llevar a cabo el ejercicio pedagógico de la decolonialidad como pacto ético. No hay didácticas prescriptivas. Sin embargo, a partir de las experiencias realizadas en el campo, se pueden estipular y comentar algunos criterios metodológicos que marcan la posibilidad de una didáctica para la pluriversalidad. 
Los arrebatos por la «objetividad» como valor supremo de la educación y, dentro de ella, por la evaluación parametrizada, son una manifestación del arquetipo dual de la modernidad clásica expresado en la subjetivación de la mente como contrapeso a la subjetivación de lo humano. En esa lógica, el exceso técnico y los diseños educativos, fundados exclusivamente en la calidad y la eficiencia, disuaden el ejercicio de un pensamiento crítico pues resulta impertinente evidenciar los quiebres de los modelos dominantes, que son los que sostienen las formas canónicas de productividad y sus respectivos modus vivendi.

Ante ello, junto a todo lo demás que se ha expuesto, una concepción central de la pedagogía decolonial es la complejidad integradora de lo humano y de lo no-humano, que contribuya a desvelar los universos del individuo, de sus vinculaciones sociales y de sus relaciones planetarias; en suma, plantear un tipo de educación que favorezca el desarrollo integral humano, el cosmopolitismo decolonial y la civilización biocentrada en un marco de globalidad intercultural, ética y democrática, trazado desde las márgenes.

Yo creo que la lucha decolonial está más bien, en este momento, en «la tierra», no en las instituciones, a las que no tenemos acceso. El trabajo es más «grassroot» [en las raíces], como se dice, y en ese sentido estar siempre atento a lo que está haciendo esta gente. En África yo estuve viendo que sí, están surgiendo muchas escuelas donde esto se está analizando, el «Grassroot Education», «Decolonial education»... y esto es lo que podemos hacer, es decir, donde trabajemos alertar a la gente de lo que significan estos criterios globales de excelencia, eficiencia, alta calidad, etc. (Mignolo, entrevistado por Argüello, 2013).

En tal resignificación de horizontes, la globalidad del siglo XXI hace explícita la pregunta sobre «cómo vivir juntos», desde la interdependencia de personas, seres, pueblos y territorios, habida cuenta de los inevitables vínculos que aparecen en la (re)construcción continua de la historia. Ante ello, «la globalidad necesita ser conceptualizada en el plano de una sensibilidad a la diferencia, y en particular a las diferencias culturales que señalan las experiencias de cada momento del tránsito histórico del colonialismo» (De Lissovoy, 2010, p.280).

Para realizar este empeño se hace necesario desarrollar un «currículo contra la dominación» (De Lissovoy) y una pedagogía decolonial que contemple propuestas prácticas para la instauración de una perspectiva integradora en educación, esto es, lugares sociales para formar una «solidaridad global» apoyada en la coexistencia, la reciprocidad y la dignidad desde la «construcción de interrelaciones no-dominantes en la diferencia» (Op. 
cit., p.279) ${ }^{30}$; una educación comprometida de facto con la materialización de la democracia, es decir, con vías de implementación y prácticas sociales, contra las formas cambiantes de fundamentalismo y la violencia de él derivada.

Aquí se entiende la tesis de Lissovoy, en resonancia a las «ontologías del habitar», según la cual las relaciones sociales restablecidas por la globalidad se acompañan de la resignificación de identidades, es decir, de un nuevo modo de ser sujetos, creando también un cuerpo de implicaciones para el plano educativo. Cuando el autor afirma que «las formas de relación no son separables de las formas de ser» (Op. cit., p. 281), se hace patente la negociación para la interdependencia y la relación recíproca en el marco de comunidades transnacionales definidas por la globalidad e incluso por la abstracción del ser-otro. En tal sentido, las relaciones con el mundo y con los otros no es «algo» que nos pasa sino «algo» que somos. Es el eje de interconexión entre la sociología, la ontología y la ética.

Una reconfiguración de las cosmovisiones desde las culturas basadas-en-lugar, recuerda que «la des-esencialización de la identidad significa asumir seriamente todas las identidades» (Escobar, 2005, p.85). Es decir, el reconocimiento de que no hay una forma canónica de ser, una identidad universal, sino una trama de multiplicidades en relación.

En tal horizonte, el currículo decolonial fundado sobre un sentido nuevo de globalidad, exige «comprender los procesos de conquista material y cultural, que constituyen algunos lugares como "periféricos" y otros como "centrales", lo cual significa descentrar al autor aparente de esta historia» (De Lissovoy, 2010, p.287). En ese marco interpretativo la cuestión del otro no puede ser definida desde criterios de estricta jerarquización; por el contrario, es menester revisar y sustituir las categorías que valoran al otro (individuo, pueblo, cultura) desde el prejuicio de la minusvalía, la inmoralidad, el atraso y las demás producciones coloniales de realidad no-existente criticadas por De Sousa en su sociología de ausencias ${ }^{31}$.

30 El estado de «solidaridad global» es el nivel de coimplicación ciudadana donde los sujetos «comienzan a reconocer las relaciones históricas, antropológicas y ontológicas -tanto en los hechos materiales, como en las posibilidades imaginativas-, que los atan con los otros, y que demanda una respuesta urgente cuando cualquiera es explotado y agredido dentro de este círculo» (De Lissovoy, 2010, p. 289).

31 La sociología de las ausencias, o lógica de no-existencia, se define desde un patrón de racionalidad monocultural con sus respectivas formas sociales (De Sousa, 2011, p.30): el ignorante (monocultura del conocimiento), el retrasado (monocultura del tiempo lineal), el inferior (monocultura de la clasificación, basada en la naturalización de las diferencias), lo local o particular (monocultura de lo universal o lo global, o lógica de la escala dominante) y el improductivo (monocultura de criterio 
La pedagogía decolonial, en el cultivo de la empatía (lovingness) para una nueva alterización, colabora con la deconstrucción de los nacionalismos fundamentalistas, las distintas modalidades de imperialismo, los centros de poder global y el combate a las prevenciones ontológicas, culturales y políticas que alimentan la «patologización de los otros» (Op. cit., p. 288). De ahí que, desde el cultivo del pensamiento crítico decolonial se opte por la conciencia de la diferencia cultural: «La teoría decolonial se relaciona con la confrontación, desafío y des-montaje de la fuerza dominadora y asimiladora del colonialismo como un proceso histórico contemporáneo, así como del eurocentrismo epistemológico y cultural en el que se sostiene» (Op. cit., p. 280).

Es un elemento central de la didáctica decolonial confrontar las políticas anglo/ eurocéntricas del conocimiento en la educación pues detrás de toda oficialidad hay un relato oculto de validación, tejido sobre cierta mirada fragmentaria de mundo y alterización. La pedagogía, antes que aliada acrítica de la colonialidad y sus retóricas, debe trabajar también con ese cúmulo de experiencias, saberes, conocimientos y prácticas de la «otra orilla», pues ellos representan una parcela de la existencia que no por ser negada puede ser ignorada o desplazada para la realización de un proyecto planetario emergente.

Desde este punto de vista, la educación como tarea social demanda la opción decolonizadora que anticipa, prepara, diseña los términos para construir un orden global resignificado, desde lo local, signado por la coexistencia y la solidaridad. Este es el carácter anticipatorio de toda educación («conciencia anticipatoria», según De Sousa) como elemento clave de la sociología de emergencias ${ }^{32}$. Valores políticos sustanciales como la coexistencia en la pluralidad, fruto de un ejercicio pleno de los derechos fundamentales, la libertad corresponsable o el compromiso histórico, no solo anhelan un lugar deseable en la indeterminación abstracta del futuro sino que ya van siendo, en las circunstancias

de la productividad y la eficiencia capitalista). Se trata de la fijación de cánones desde los criterios hegemónicos de racionalidad, verdad y eficiencia, fuera de los cuales solo queda la inexistencia (De Sousa, 2011, p. 32).

32 En contrapartida a la sociología de ausencias, «la sociología de las emergencias consiste en la investigación de las alternativas que caben en el horizonte de las posibilidades concretas» (De Sousa, 2011, p.33), extendiendo el sentido de la realidad hacia posibilidades y expectativas presentes. «La ampliación del presente implica la contracción del futuro, en la medida en que lo Todavía-No, lejos de ser un futuro vacío e infinito, es un futuro concreto, siempre incierto y siempre en peligro» (De Sousa, 2011, p.33). La sociología de las emergencias, sostenida en la idea axiológica del cuidado (De Sousa, 2011, p.34), es conciencia anticipadora en el horizonte de las posibilidades. 
de cada «aquí y ahora», de manera que la opción decolonial antes de ser un destino es un itinerario ${ }^{33}$. En este punto se hace fundamental una pedagogía que no solo propicie sino que realice, en cada escenario concreto de sus actuaciones, el auténtico respeto a la diferencia como principio ético fundamental para la construcción progresiva de la comunidad global e intercultural.

En suma, la posibilidad de una didáctica de la decolonialidad, en orden a la consecución pública-democrática del mundo pluriversal, se puede sintetizar en los siguientes criterios estratégicos:

1. Los empeños por la decolonización del saber, donde se tejen las perspectivas y maneras de entender el mundo. Es el problema de la construcción del conocimiento y las nuevas genealogías conceptuales que suscita la acción decolonial, «puesto que los Huntingtons (para la derecha) y los Zizeks, los Laclaus, los Bourdieus (o aún mejor, los Giddens que asesoran a Blair y los Becks que asesoran a Schroeder) ya no pueden ser quienes guían el pensamiento crítico del "otro lado" de la diferencia colonial» (Mignolo, citado en Walsh, 2003, p.24).

Este llamado de Mignolo a reorientar los principios y propósitos de la investigación y la enseñanza se expresa en tres núcleos problémicos que no podrían obviarse en ninguna formulación ni práctica educativa:

- ¿Qué tipo de conocimiento/comprensión (epistemología y hermenéutica) queremos/necesitamos producir y transmitir? ¿Con quiénes y para qué?

- ¿Qué métodos/teorías son relevantes para el conocimiento/comprensión que queremos/necesitamos producir y transmitir?

- ¿Con qué fines queremos/necesitamos producir y transmitir tal tipo de conocimiento/comprensión? (Op. cit., p. 21).

33 La imaginación ético-pedagógica, impulsada por la decolonialidad, no tiene un talante de abstracción quimérica, sino que es en sí misma la configuración sustantiva del carácter anticipatorio de la educación, un pensar-siendo, que conlleva la transformación gradual de prácticas, discursos y sensibilidades. Se contienen aquí «las posibilidades generativas de trabajar desde los intersticios de las identidades y de las culturas para una enseñanza emancipadora y multicultural» (De Lissovoy, 2010, p. 288). 
A este programa didáctico de escrutinio de la fundamentación/acción educativa subyace la vía decolonial del desprendimiento y la apertura: lo que hay que dejar, lo que hay que reconciliar y bajo qué procedimientos se lleva a cabo la interlocución (How do you delink decolonially):

Primero se necesita construir conocimiento y argumentos que sustituyan la hegemonía actual del conocimiento occidental. Es esta hegemonía la que justifica, a su vez, la hegemonía del capitalismo y del Estado, y que establece el desarrollo como una condición de libertad [...]. Es necesario construir argumentos convincentes para que las personas perciban que el «desarrollo» es una opción, justificada por actores, categorías de pensamiento, instituciones, los medios, etc. Es una opción pero no la única (Mattison, 2012).

2. Los empeños por la decolonización del ser, esto es, de las identidades por el acercamiento a la experiencia donde cobran relevancia las metodologías de tipo narrativo y biográfico de las ciencias sociales, que se centran en el mundo vital del sujeto antes que en las formas establecidas del método mismo. Las metodologías se someten a cosmovisiones epistémicas, pues aisladas corren la suerte de didácticas insulares: se convierten en modas inconexas proclives a desapariciones fugaces sin aportar a la consolidación de iniciativas. Puesto que se requiere la continuidad en la afectación de estamentos, mentalidades y criterios, la tarea académica/intelectual de la decolonialidad deberá reformularse en términos epistémicos, éticos y políticos, de donde broten métodos enlazados con las situaciones vitales de frontera.

En tal perspectiva, el potencial de la biografía es clave al construir las genealogías del locus de enunciación en situaciones coloniales pues desvela el proceso de los lugares de dominación, no solo desde la historia personal del sujeto sino también desde los roles sociales y las funciones institucionales en las coordenadas de poder, género, raza, clase social, sistemas de creencias, afiliación política y otros vectores de subjetivación. El uso y acercamiento biográfico en la decolonización del ser favorece una postura no determinista en razón de lugar, prejuicio o antecedentes. Incentiva, así, el cuidado hermenéutico en torno a la progresiva localización geohistórica y vital para comprender las «subjetividades de frontera».

De esta manera, la potencialidad biográfica en el giro decolonial tiene, al menos, dos alcances de especial importancia. Por un lado, según se ha dicho, sus metodologías establecen contacto desideologizado con el mundo vital del sujeto, con sus maneras de ser sí mismo, de construir comunidad y apreciar la historia. Contra las retóricas de la modernidad, la biografía es el relato de la experiencia, de las memorias y de la recuperación 
del espacio desde el cual es posible pensar la «herida colonial» justamente porque las memorias se resisten a ser colonizadas; esto es, seguir el pensamiento que surge en las «voces del mundo»34.

El otro aporte es que el enfoque biográfico, por su principio de hermenéutica de la interacción (Ferrarotti), permite confrontar la vida local con el paradigma moderno establecido, toda vez que el ideario decolonial se funda en la tensión desprendimientoapertura. Como se ha expuesto, el giro decolonial sustenta un proyecto histórico para la coexistencia en la pluralidad; no para la anulación o la tercerización. No es el rechazo de ciertas formas de ser para la prevalencia de otras, sino la coexistencia de todas las formas posibles. La pedagogía decolonial se pregunta, entonces, cómo construir desde la educación narrativas que, en la perspectiva del sistema-mundo moderno/colonial, se orienten hacia la comprensión de lógicas diferentes, a la restauración y reconocimiento de los pensamientos e identidades de frontera.

La perspectiva biográfica tiene el potencial de registrar el intersticio de la diferencia colonial, por cuanto aborda los planos interconectados -más aún, sobrepuestos- de las identidades, conciencia de sí, relacionalidad y patrones de convivencia. La comprensión de la diferencia colonial es un espacio epistemológico y político privilegiado que escapa a los alcances de la razón universal. «En otras palabras, lo que emerge de este encuadre alternativo es la necesidad de tomar seriamente la fuerza epistemológica de las historias locales y pensar lo teórico a través de la praxis política de los grupos subalternos» (Escobar, 2005, p.35)35.

Es así como en la biografía aflora la «plataforma de la pluriversalidad» (Mignolo), la experiencia de historias locales que reaccionan a la expansión anglo/eurocéntricaoccidental a partir de la «necesidad de edificar narrativas desde la perspectiva de la modernidad/colonialidad» (Op. cit., p. 36).

34 Los estudios biográficos afrontan el desafío de pensar desde el lugar de la «herida colonial», de ayer como hoy: «La historia del colonialismo desde la perspectiva de los actores que lo vivieron en las colonias (criollos, mestizos, indígenas o afroamericanos), como sus equivalentes en África y Asia, son los lugares epistémicos donde surge "un paradigma otro"» (Mignolo, 2003, p. 22).

35 Desde los lineamientos del análisis político de Escobar se puede desarrollar la idea de la biografía como itinerario epistemológico, que contribuye a explorar nuevas formas de ser y de pensar, es decir, a la comprensión de la decolonialidad desde la categoría de «intersticios de la diferencia colonial». La biografía resulta un dispositivo metodológico pertinente ante «la necesidad de considerar seriamente la fuerza epistemológica de las historias locales y de pensar la teoría desde la praxis política de los grupos subalternos» (Escobar, 2005, p.72). 
3. En el plano de la educación formal, los empeños por la decolonización del currículo, es decir, la exigencia por diseños curriculares de tipo transdisciplinar y problémico en horizonte bioético/planetario como una manera de confrontación de las disciplinas fundadas en epistemologías del poder (para De Sousa, episteme transdisciplinar emergente, Márquez-Fernández, 2012, p.84). El hiperespecialismo, una de sus más claras expresiones, se caracteriza por la fijación totalizante en determinado objeto de estudio que impide su inscripción en un panorama de complejidad e interacción. Al confundir realidad con «objetividad monológica», promueve el desarrollo de currículos cerrados a todo aquello que no se considera estrictamente unido al campo de «la disciplina».

En contrapartida, el «currículo contra la dominación» conlleva una referenciación contrahegemónica del conocimiento, es decir, promueve la interdependencia de conocimientos «científicos» $\mathrm{y}$ «no-científicos», «rentables» e «improductivos» bajo un supuesto de incompletud de las ciencias e indeterminación del fenómeno humano. Ello implica considerar las limitaciones del pensamiento, los vacíos del saber humano (ignorancias parciales) y la necesidad de un «método relativista» que permita apreciar los descentramientos de la verdad o, lo que es lo mismo, la imposibilidad de un único estatuto de la misma ${ }^{36}$.

El currículo decolonial actúa como dispositivo pedagógico para integrar a los desarrollos educativos formales una tramitación democrática de las inscripciones sociales, las herencias culturales y las conformaciones planetarias donde se está vinculado, en clave revisionista de las racionalidades definidas por el universalismo y la homogeneidad del conocimiento. En tal sentido, «las investigaciones transdisciplinares o posdisciplinares, son las que portan esa otra episteme de racionalidades que en su desenvolvimiento dialéctico, holístico, transversal, están en capacidad para producir los cambios sustantivos de nuestra representación del mundo» (Op. cit., p. 87).

La perspectiva decolonial en el plano curricular afecta, inevitablemente, los modos de entender los agentes de la educación y sus relaciones (escolares, maestros, instituciones

36 Sobre la fragmentación de la idea de verdad científica definitiva y su consecuente provisionalidad de las epistemologías de acuerdo con los objetos de estudios, existe una amplia discusión en las ciencias sociales emparentada con la acusación relativista. Al respecto es valioso el análisis de Grimson, Merenson y Noel (2011, p.12) al comentar: «Ritualmente, hay que señalar que el relativismo metodológico no implica ni un relativismo moral ni un nihilismo epistemológico. No resulta tan evidente que, detrás de la exigencia de aclarar esta diferencia una y otra vez, se esconde agazapada una profunda resistencia a cualquier búsqueda seria de comprensión de la diferencia». 
educativas, organizaciones civiles, etc.). Ya no se trata de considerar el dilema pedagógico como un problema de instrucción sino de comunidades que optan por la formación de conciencia para la participación:

La cuestión no es darles conocimientos sino darles los instrumentos para que ellos entiendan cómo es, cómo se maneja la [matriz colonial del poder] [...]. Nuestra tarea es ofrecerles los instrumentos, no lo que tienen que pensar, sino los instrumentos para que ellos piensen... para que ellos articulen lo que ya saben; lo saben por intuición, pero no tienen el discurso [...] tenés [sic] que darles los instrumentos para que ellos puedan enfrentarse con la sociedad que los oprime: los instrumentos de conocimiento con los que ellos puedan argumentar (Mignolo, entrevistado por Argüello, 2013).

En esta tarea de propiciar un «conocimiento científico que haga más humanizadas las relaciones sociales entre los seres humanos» (Márquez-Fernández, 2012, p.9o), por la confrontación de las lógicas absolutistas, juega un papel fundamental la formación en deportes, artes y humanidades como función sustantiva de las llamadas «funciones sustantivas» de la educación actual. Valiosa ha sido la contribución de la filósofa norteamericana Martha Nussbaum a este propósito:

Si no insistimos en la importancia fundamental de las artes y las humanidades, éstas desaparecerán, porque no sirven para ganar dinero. Sólo sirven para algo mucho más valioso: para formar un mundo en el que valga la pena vivir, con personas capaces de ver a los otros seres humanos como entidades en sí mismas, merecedoras de respeto y empatía, que tienen sus propios pensamientos y sentimientos, y también con naciones capaces de superar el miedo y la desconfianza en pro de un debate signado por la razón y la compasión (Nussbaum, 2010, p.189).

En esta propuesta didáctica se destaca la complicidad natural de las humanidades con el cultivo del deporte, las artes y las letras, pues mantienen la alerta ante la precariedad de la existencia al tiempo que propician la comprensión y ejercicio de la sociedad pluriversal. Esta alianza cultural de las humanidades estimula la capacidad de comprensión y expresión ante el mundo propio y el circundante: redescubre la trivialidad como relato oculto de la vida, restablece los motivos del pensar y brinda elementos para salir de la inercia heredada de las costumbres (Argüello, 2013c, p. 28). 
4. Los empeños por la decolonización de las prácticas socioculturales, para escudriñar como comunidad de indagación territorios atípicos de sociedad, cultura, representación y conocimiento. Pero no basta escudriñar separadamente. También es necesario percibir las intersecciones epistémicas con los relatos dominantes, con los lugares de colonización:

Una de las urgencias educativas del planeta es construir proyectos educativos que trabajen de alguna manera con el «border thinking». La cuestión es que los proyectos educativos hoy están controlados por la modernidad, entonces todo va a hacer de los estudiantes «personas eficientes» dentro de un sistema. La cuestión es que hay que darle al estudiante instrumentos para que entienda que el mundo es así, pero no tiene que ser necesariamente así; que el mundo es así hoy porque está gobernado [por la lógica de la modernidad]. Ese es el gran desafío, por un lado. Pero no es disociarse de la modernidad sino reducirla a sus justos términos. Reducir la modernidad en lo que fue en sus periodos históricos. Ahora están surgiendo todos estos conocimientos en todas partes del mundo, pero al mismo tiempo tienen que articularse... tienen que jugar como hizo China con el capitalismo, tienen que «robar» la modernidad para pensar por sí mismos (Mignolo, entrevistado por Argüello, 2013b).

En este orden de ideas, el compromiso de la pedagogía decolonial en la reconstrucción social exige cultivar los hábitos mentales que requiere la diferencia cultural, como paso previo a la activación de «zonas de contacto» intercultural. Para llevar a cabo ese programa, se deben atender, por lo menos, los siguientes niveles:

- Reconocimiento. Reconocer que el mundo-otro existe: las economías, las sexualidades, las creencias, las gobernabilidades, en suma, las polifonías de la existencia y de las culturas. Para adelantar esta etapa elemental de la pluralidad es necesario detectar y combatir, por vías dialógicas y participativas, los modos explícitos o tácitos de la dominación estructural, esto es, las formas prácticas de la matriz colonial del poder. Esta es la razón de ser de la formación del pensamiento crítico decolonial o «pensamiento crítico de frontera» (Walsh).

- Intersección. Indagar cómo el mundo-otro es también un mundo propio mediante el estudio comparado de las tradiciones coloniales y de las alternativas decoloniales. La historia oculta de las relaciones, o genealogías experienciales del poder, más que las historias oficiales, contribuyen a ilustrar que no hay legitimación de 
colonialidad sin sometimiento de dominados y que, por lo tanto, estos no son una abstracción de los discursos ni un simple «daño colateral» del progreso.

- Interacción. Una vez se identifican las relaciones de poder en las que se ha formado la historia, se requiere desarrollar, transdisciplinarmente, la opción decolonial desde el paradigma de la coexistencia, más allá de la jerarquización, que contemple una visión ética de cultura y de sociedad no definidas por la marginalización sino por la conversación de lo plural: «El sujeto de la diferencia colonial no es un sujeto indiferenciado, género-neutral (o diferenciado sólo en términos de raza y clase). Existen diferencias en la forma en la cual los grupos subalternos son objetos de poder y sujetos de agencia» (Escobar, 2005, p.83). Esto exige precisar el «desde dónde» de las subjetividades de frontera y las políticas culturales de la diferencia; los dinamismos de conformación y transformación de la colonialidad.

En conclusión, la pedagogía decolonial se puede entender como el andamiaje social que prepara y lleva a cabo la viabilidad de «un paradigma-otro» desde un movimiento complejo y multidireccional que tome en cuenta (Mignolo, 2003, p. 52):

- La inseparabilidad modernidad/colonialidad

- Generar conciencia de la colonialidad del poder

- De lo anterior, provocar conciencia de la diferencia colonial

- Percibir la relación entre producción de conocimientos y procesos de descolonización y de socialización del poder.

En el alcance de estos postulados, se instala la importancia de la relación biografíaeducación-decolonialidad. A diferencia de enfoques como la historia oral, no se trata solamente de la exposición del lugar de la frontera, que contemplaría aún la noción moderna de un sujeto reificado desde el buen intento por el reconocimiento, la visibilidad y la inclusión social. La biografía decolonial está vinculada a la genealogía del lugar de enunciación, es decir, explicita la posicionalidad del conceptualizador, desvela su lugar y su espacio, evidencia sus propias contradicciones e intereses (Garcés, 2005, p. 160), en una palabra, contribuye al desmontaje de la vertebración absoluta del poder y a la emergencia de las alteridades. La biografía decolonial está orientada a la transformación de costumbres, al derrocamiento de prejuicios, a la conversión de parálisis paradigmáticas, heredadas de la modernidad.Desde esta mirada, la educación tiene una función ineludible en el proyecto decolonial de la pluriversalidad «centrada en historias locales en las cuales los designios 
globales coloniales son necesariamente transformados. La diversidad de la mundialización es contrastada acá con la homogeneidad de la globalización, tendiente hacia múltiples y diversos órdenes sociales, en síntesis, pluriversalidad» (Escobar, 2005 Op. cit., p. 37). La opción decolonial tiene que movilizar la educación entre el mandato eficientista definido por el paradigma del rendimiento transnacional, como fuerza de trabajo y producción de capital financiero; y, por otro lado, la minucia humana de la existencia, la «elección de lo pequeño» (Reyes, 2008, p.16), las configuraciones simbólicas y los imperativos éticos contemporáneos. Se trata de una educación no solo para enfrentar la globalidad, que en último término es una forma sutil de sometimiento, sino para comprender su complejidad y la manera de (re)hacer historia ante los legados de los imperialismos a lo largo del tiempo.

\section{Referencias}

Aguiló, A. (2009). La universidad y la globalización alternativa: justicia cognitiva, diversidad epistémica y democracia de saberes. En Nómadas. Revista crítica de ciencias sociales y jurídicas, 22(2), 5-28.

Argüello, A. (2015). Pedagogía decolonial: Trazos para la construcción de un paradigma-otro desde la educación. Revista Correo del Maestro, 19(226), 28-37.

Argüello, A. (2013). Entrevista realizada a Walter Mignolo, el 9 de octubre de 2013, en Center for Global Studies and Humanities, Duke University, Durham, NC., USA.

Argüello, A. (2013b). Entrevista realizada a Walter Mignolo, el 16 de octubre de 2013, en Durham, NC., USA.

Argüello, A. (2013c). Educación Humanista-compleja: tribulaciones y magisterios de la cotidianidad. En Conferencia en el Foro Educativo La invención cotidiana de la escuela. Bogotá.

Baker, M. (2012). Modernity/Coloniality and Eurocentric Education: Towards a Post-occidental Selfunderstanding of the Present. En Policy Futures in Education, 1o(1), 4-22. Recuperado de: www. scopus.com

Barberà, J. (2011). Entrevista realizada a Eduardo Galeano, el 24 de mayo de 2011 en el Programa catalán Singulars. Recuperada de: https://www.youtube.com/watch?v=ICsnSAyJABY

De Lissovoy, N. (2010). Decolonial Pedagogy and the Ethics of the Global. En Discourse: Studies in the Cultural Politics of Education, 31(3), 279-293. Recuperado de: www.scopus.com

De Sousa Santos, B. (2002). Hacia una concepción multicultural de los derechos humanos. En El otro derecho, (28). 
De Sousa Santos, B. (2003). The World Social Forum: Toward a Counter-Hegemonic Globalization. Presentada en XXIV International Congress of the Latin American Studies Association, 236-343. De Sousa Santos, B. (2006). The rising of the global letf: The World Social Forum and Beyond. Londres: Zed Books.

De Sousa Santos, B. (2011). Epistemologías del Sur. En Utopía y praxis latinoamericana, 16(54), 17-39.

Dussel, E. (2003). Beyond philosophy: Ethics, History, Marxism, and Liberation Theology. Lanham, MD: Rowman \& Littlefield.

Escobar, A. (2012). Una minga para el postdesarrollo: lugar, medio ambiente y movimientos sociales en las transformaciones globales. Bogotá: Ediciones desde abajo.

Escobar, A. (2005). Más allá del Tercer Mundo. Globalización y diferencia. Bogotá: ICANH Universidad del Cauca.

Garcés, F. (2005). Las políticas del conocimiento y la colonialidad lingüística y epistémica. En Pensamiento crítico y matriz (de)colonial. Reflexiones latinoamericanas (pp. 135-167). Quito: Universidad Andina Simón Bolívar - Ediciones Abya Yala.

Grimson, A.; Merenson, S.; Noel, G. (2011). Descentramientos teóricos. En Antropología ahora. Debates sobre la alteridad (pp. 9-31). Buenos Aires: Siglo XXI Editores.

Haraway, D. J. (1995). Ciencia, cyborgs y mujeres. La reinvención de la naturaleza. Madrid: Cátedra.

Hinkelammert, F. (2010). Yo soy, si tú eres. El sujeto de los derechos humanos. México: Centro de Estudios Ecuménicos.

Khatibi, A. (1990). Love in Two Languages. Minneapolis: University of Minnesota Press.

Márquez-Fernández, Á. (2012). Alternativas epistémicas para las ciencias sociales desde el Sur. En Revista de Filosofía 7o(1), 83-97.

Mattison, C. (2012). Delinking, decoloniality and dewesternization. Entrevista con Walter Mignolo. Recuperada de: http://criticallegalthinking.com/2012/05/o2/delinking-decoloniality-dewester nization-interview-with-walter-mignolo-part-ii/

Mignolo, W. (2012). Local histories/Global designs. Coloniality, Subaltern Knowledges, and Border Thinking. Princeton: Princeton University Press.

Mignolo, W. (2011). La colonialidad a lo largo y a lo ancho: el hemisferio occidental en el horizonte colonial de la modernidad. En La colonialidad del saber: eurocentrismo y ciencias sociales. Perspectivas Latinoamericanas (pp. 73-104). Buenos Aires: CICCUS/CLACSO.

Mignolo, W. (2010). Cosmopolitanism and the De-colonial Option. En Studies in Philosophy and Education, 29(2), 111-127. Recuperado de: www.scopus.com

Mignolo, W. (2009). El lado más oscuro del Renacimiento. En Universitas Humanística, (67), 165-203. 
Mignolo, W. (2009b). El pensamiento decolonial, desprendimiento y apertura. En Dussel, E., Mendieta, E., Bohórquez, C.(eds), El pensamiento filosófico latinoamericano, del Caribe y "latino" (13oo20oo): historia, corrientes, temas y filósofos (pp. 659-672). Siglo XXI: Centro de Cooperación Regional para la Educación de Adultos en América Latina y el Caribe.

Mignolo, W. (2009c). Epistemic Disobedience, Independent Thought and Decolonial Freedom. Theory, Culture and Society, 26(7-8), 159-181. Recuperado de: www.scopus.com

Mignolo, W. (2005). The idea of Latin America. Malden, MA: Blackwell Publishing.

Ministerio de Educación Nacional (MEN). Educación de calidad. El camino para la prosperidad. Recuperado de: http://www.mineducacion.gov.co/cvn/1665/articles-237397_archivo_pdf.pdf

Mignolo, Walter (2003). Un paradigma otro: colonialidad global, pensamiento fronterizo y cosmopolitismo crítico. En Historias locales/diseños globales. Colonialidad, conocimientos subalternos y pensamiento fronterizo (pp. 19-6o). Madrid: Akal.

Nussbaum, M. (2010). Sin fines de lucro. Por qué la democracia necesita de las humanidades. Madrid: Katz Ediciones.

Lander, E. (2011). Ciencias sociales: saberes coloniales y eurocéntricos. En La colonialidad del saber: eurocentrismo y ciencias sociales. Perspectivas Latinoamericanas (pp. 15-44). Buenos Aires, CICCUS/CLACSO.

León-Portilla, M. (Ed) (2011). Huehuehtlahtolli. Testimonios de la antigua palabra. Recogidos por fray Andrés de Olmos hacia 1535. México: Fondo de Cultura Económica.

Quijano, A.(2011). Colonialidad del poder, eurocentrismo y América Latina. En La colonialidad del saber: eurocentrismo y ciencias sociales. Perspectivas Latinoamericanas (pp. 219-264). Buenos Aires: CICCUS/CLACSO.

Reyes Mate, M. (2008). La herencia del olvido. Madrid: Errata naturae.

Walsh, C. (2003). Las geopolíticas del conocimiento y colonialidad del poder. Entrevista a Walter Mignolo. Polis. En Revista de la Universidad Bolivariana, 1(4), 1-26. Recuperado de: http://www. redalyc.org/articulo.oa?id=30500409

Walsh, C. (2013). Pedagogías decoloniales: prácticas insurgentes de resistir, (re)existir y (re)vivir. Tomo I. Quito: Ediciones Abya-Yala. 